\title{
Endometrial cancer gene panels: clinical diagnostic vs research germline DNA testing
}

\author{
Amanda B Spurdle ${ }^{1}$, Michael A Bowman ${ }^{1}$, Jannah Shamsani ${ }^{1}$ and Judy Kirk ${ }^{2}$ \\ ${ }^{1}$ Molecular Cancer Epidemiology Laboratory, Genetics and Computational Biology Division, Genetics and \\ Computational Biology Department, QIMR Berghofer Medical Research Institute, Herston, QLD, Australia and \\ ${ }^{2}$ Familial Cancer Service, Crown Princess Mary Cancer Centre, Westmead Hospital, Sydney Medical School, \\ University of Sydney, Centre for Cancer Research, The Westmead Institute for Medical Research, Westmead, \\ NSW, Australia
}

\begin{abstract}
Endometrial cancer is the most common gynecological cancer, but is nevertheless uncommon enough to have value as a signature cancer for some hereditary cancer syndromes. Commercial multigene testing panels include up to 13 different genes annotated for germline DNA testing of patients with endometrial cancer. Many other genes have been reported as relevant to familial endometrial cancer from directed genome-wide sequencing studies or multigene panel testing, or research. This review assesses the evidence supporting association with endometrial cancer risk for $\mathbf{3 2}$ genes implicated in hereditary endometrial cancer, and presents a summary of rare germline variants in these 32 genes detected by analysis of quasi-population-based endometrial cancer patients from The Cancer Genome Atlas project. This comprehensive investigation has led to the conclusion that convincing evidence currently exists to support clinical testing of only six of these genes for diagnosis of hereditary endometrial cancer. Testing of endometrial cancer patients for the remaining genes should be considered in the context of research studies, as a means to better establish the level of endometrial cancer risk, if any, associated with genetic variants that are deleterious to gene or protein function. It is acknowledged that clinical testing of endometrial cancer patients for several genes included on commercial panels may provide actionable findings in relation to risk of other cancers, but these should be considered secondary or incidental findings and not conclusive evidence for diagnosis of inherited endometrial cancer. In summary, this review and analysis provides a comprehensive report of current evidence to guide the selection of genes for clinical and research gene testing of germline DNA from endometrial cancer patients.

Modern Pathology (2017) 30, 1048-1068; doi:10.1038/modpathol.2017.20; published online 28 April 2017
\end{abstract}

Endometrial cancer is the most common gynecological cancer, affecting 1 in 37 women in the United States ${ }^{1}$ and 1 in 49 in Australia ${ }^{2}$ during their lifetime, signifying a 2 to $3 \%$ lifetime risk. Historically, endometrial cancers have been divided into two cellular classifications: type I tumors are associated with unopposed estrogen stimulation and are mostly endometrioid adenocarcinomas, whereas type II tumors are estrogen independent consisting of predominantly serous carcinomas. The endometrioid subtype accounts for $80 \%$ of endometrial cancers,

Correspondence: Dr AB Spurdle, PhD, Molecular Cancer Epidemiology Laboratory Genetics and Computational Biology Division, Genetics and Computational Biology Department, QIMR Berghofer Medical Research Institute, 300 Herston Road, Herston, QLD 4006, Australia.

E-mail: Amanda.Spurdle@qimrberghofer.edu.au

Received 24 November 2016; revised 7 February 2017; accepted 9

February 2017; published online 28 April 2017 the serous subtype accounts for $10 \%$, and the remainder include mucinous, clear-cell, squamous cell, and mixed adenocarcinomas. ${ }^{3}$ Recently, largescale molecular analysis of endometrial tumors grouped endometrial cancers into four molecular classifications: POLE-ultramutated, microsatellite instability (MSI)-hypermutated, copy-number low, and copy-number high. ${ }^{4}$

Factors that have been linked to an increase in endometrial cancer risk of all subtypes combined include long-term exposure to unopposed estrogens, age at menarche, age at menopause, nulliparity, obesity, diabetes, ${ }^{5}$ and long-term use of tamoxifen as a treatment for breast cancer. ${ }^{6}$ Individuals who have a first-degree relative with endometrial cancer are at increased risk of the disease, with a relative risk (RR) of 1.8 (1.7-2.0) estimated from a meta-analysis of 16 different studies of varying design and age range. ${ }^{7}$ Familial risk of endometrial cancer may, in part, be due to shared environmental risk factors, for 
example, obesity due to shared lifestyle choices. However, it is clear that familial risk of endometrial cancer is influenced by genetic factors, ranging from inheritance of multiple low-risk cancer predisposition variants to single, very high-risk variants. To date, several common single-nucleotide polymorphisms (SNPs) have been shown to be convincingly associated with endometrial cancer risk from largescale candidate locus analysis and genome-wide association analyses. These include 'low-risk' SNPs at/near $H N F 1 B,^{8,9}$ the TERT-CLPTM1L cancer risk region, ${ }^{10}$ the $C Y P 19 A 1$ locus encoding the aromatase enzyme pivotal to estrogen biosynthesis, ${ }^{11}$ ESR1 encoding the estrogen receptor, ${ }^{12} \mathrm{SH} 2 \mathrm{~B} 3,{ }^{13} \mathrm{SOX} 4,{ }^{14}$ and also KLF5, AKT1, EIF2AK4, HEY2/NCOA7, and at the $M Y C$ multicancer locus. ${ }^{15}$ Consistent with findings for most other cancers, the endometrial cancer risks associated with these common variants are considered modest (odds ratios ranging from 0.84 to 1.27). Taken together, loci identified to date are expected to account for $\sim 5 \%$ of the familial RR of endometrial cancer. Of more direct clinical significance, some endometrial cancer cases are attributable to pathogenic (disease-causing) changes in hereditary cancer predisposition syndrome genes, which confer a moderate to high lifetime risk of endometrial and other syndromic cancers. Testing of germline DNA for pathogenic variants in these syndrome genes has been undertaken largely in the familial cancer setting, and results are used to direct genetic counseling and clinical management of cancer patients and their relatives.

In recent years, many service providers have modified their germline DNA screening strategies for the genetically heterogeneous cancers and cancer syndromes from stepwise molecular analysis of a limited number of highly relevant genes to targeted multigene panel testing using next-generation sequencing. This paradigm shift has been mainly driven by advances in sequencing technology, implementation of optimized analysis pipelines, and significantly reduced sequencing costs, which have collectively resulted in more efficient, sensitive, and cost-effective genetic testing. When targeting a specific cancer type such as endometrial cancer with multiplex gene panel testing, a major challenge is gene selection. The test should be a way of identifying disease etiology and should provide actionable data with the potential to lead to clinical options for the patients and their genetic carrier relatives, such as risk-reducing surgery, targeted therapy, increased surveillance, and/or chemoprevention. This has to be balanced with generating unwanted or uninterpretable information that is not clinically useful. However, there are increasing numbers of genes purported to be associated with modest $(<2$-fold) or moderate $(2-4-$ fold) cancer risks, ${ }^{16}$ often based on limited data. Indeed, the need for clinical validation of genomic tests has been highlighted recently, in relation to breast cancer risk prediction. ${ }^{17}$ The inclusion of tenuously risk- associated genes on a multigene panel is subject for debate, as identification of variants considered deleterious to protein function in these genes will often lead to their inclusion in clinical reports, despite the dearth of evidence of their association with risk of specific cancer types, and even sometimes with any cancer type. Such practice confounds genetic counseling and clinical management of patients and their relatives. ${ }^{18-20}$

To our knowledge, only one commercial gene panel is marketed specifically for germline DNA testing when the diagnosis is endometrial cancer. The Endometrial Cancer Panel from GeneDx currently includes 12 genes: MLH1, MSH2, MSH6, PMS2, EPCAM (dosage analysis only), phosphatase and tensin homolog (PTEN), BRCA1, BRCA2, MUTYH, CHEK2, TP53, and POLD1. The GYNplus panel of 13 genes marketed by Ambry Genetics for ovarian and endometrial cancer germline DNA testing includes four additional genes currently annotated for ovarian cancer risk only (PALB2, BRIP1, RAD51C, and RAD51D), but not MUTYH, $C H E K 2$, and $P O L D 1$. There are also other nonspecific cancer panels marketed for germline DNA testing of patients with multiple cancer types including endometrial cancer, two of which (Myriad myRisk, ColorGenomics), have annotated STK11 as an additional gene relevant for endometrial cancer risk. Here we review the evidence to support the inclusion of these genes in testing panels marketed for diagnostic genetic testing of germline DNA from endometrial cancer patients and their relatives. We also review the evidence to support clinical or research germline testing of additional genes implicated in familial or unselected endometrial cancer from directed exome sequencing of familial cases, or multigene panel testing. Also, for all these genes, known or purported to be associated with risk of developing endometrial cancer, we include an analysis of germline variants identified in 543 quasi-population-based endometrial cancer patients from The Cancer Genome Atlas Project (TCGA), ${ }^{4}$ to provide additional support for our recommendations based on the review of the literature.

\section{Genes on panels marketed for diagnostic genetic testing of endometrial cancer patients}

\section{MLH1, MSH2/EPCAM, MSH6, and PMS2}

Pathogenic variants that disrupt the function of the mismatch repair (MMR) genes MLH1, MSH2, MSH6, or PMS2 confer a predisposition to Lynch syndrome, a dominantly inherited susceptibility to colorectal, endometrial, and other cancers. In addition, certain partial $3^{\prime}$ deletions of EPCAM, a gene that lies directly upstream of $\mathrm{MSH} 2$, cause epigenetic silencing of MSH2 leading to tissue-specific MSH2 deficiency in EPCAM-expressing tissues. ${ }^{21}$ When 
the MMR system is lost in a cell, the replication machinery has the inability to remove erroneous nucleotide incorporations during DNA replication, which leads to the accumulation of somatic changes throughout the genome. MSI is a consequence (hypermutability at simple, tandemly repeated sequences), which drives tumorigenesis by disrupting genes that are important for normal cellular function, such as those with roles in apoptosis and DNA repair. ${ }^{22}$ MSI in tumor DNA is thus the molecular signature of an MMR defect and arises via the following mechanisms: (1) constitutional loss of one MMR allele and subsequent somatic loss of the wild-type allele, as in Lynch syndrome; (2) hypermethylation of the $M L H 1$ gene promoter in combination with a second somatic hit to the other allele, estimated to occur in $20 \%$ of sporadic endometrial cancers; ${ }^{23}$ (3) biallelic somatic loss of at least one MMR gene. ${ }^{24-26}$ The histology of Lynch syndrome-associated endometrial cancer is heterogeneous, with the tumors being both endometrioid and non-endometrioid. Histologic subtypes include endometrioid adenocarcinoma, clear-cell carcinoma, uterine serous papillary carcinoma, and uterine carcinosarcoma. ${ }^{27,28}$ Although there has been some debate in the literature to suggest that carriers of a pathogenic MMR gene variant mostly develop endometrial cancer of non-endometrioid subtype, larger population-based studies have not provided convincing support for this hypothesis. ${ }^{23,29}$

Germline defects in MMR genes underlie the etiology of $<5 \%$ of endometrial cancer at a population level (summarized in Buchanan et $\mathrm{al}^{30}$ ). Women with an MMR defect have a high endometrial cancer lifetime risk comparable to the risk of colon cancer, ${ }^{31}$ with the lifetime risk being influenced by which MMR gene is disrupted. The cumulative risk of endometrial cancer for women to age 70 years is estimated to be $18 \%(9-34 \%)$ for $M L H 1,30 \%$ (18-45\%) for MSH2 pathogenic variant carriers, ${ }^{32}$ $26 \%(18-36 \%)$ for MSH6 pathogenic variant carriers $^{33}$ (although the risk has been estimated to be as high as $71 \%^{34}$ ), and $12-15 \%$ for PMS2 pathogenic variant carriers. ${ }^{35,36}$ A cohort study of EPCAM deletion-positive Lynch syndrome patients estimates the endometrial cancer risk to be lower than for patients with a pathogenic change in an MMR gene, as only three of 92 women with $3^{\prime}$ deletion of EPCAM developed endometrial cancer, which equates to a cumulative lifetime risk of $12 \%$ (0-27\%). ${ }^{37}$ The EPCAM deletions in all three patients extended close to the MSH2 gene promoter, suggesting that an increased risk of endometrial cancer is dependent on the location of the EPCAM deletion in relation to $\mathrm{MSH} 2$.

The clinical management recommendations for those identified to have a Lynch syndromeassociated pathogenic genetic variant include colonoscopy every 1 to 2 years, and (in some centers) gynecological examination (with transvaginal ultrasound, and aspiration biopsy) on a yearly basis. ${ }^{38}$
Risk-reducing gynecological surgery is an option for women from age 35 and generally recommended after childbearing is completed. ${ }^{38}$ The high risks of endometrial cancer for women with a germline defect in MLH1, MSH2, MSH6, and PMS2-in addition to EPCAM dosage analysis-make these genes obvious inclusions on an endometrial cancerfocused panel.

\section{POLD1 (and POLE)}

The POLD1 and POLE genes encode subunits of DNA polymerases $\delta$ and $\varepsilon$, respectively, which are part of the DNA replication machinery and are involved in the recognition and removal of mispaired bases that occur during DNA replication. Palles et $a l^{39}$ analyzed the exomic variants of several individuals with multiple colorectal adenomas and family histories of cancer that were not accounted for by pathogenic variants in $A P C, M U T Y H$, or the MMR genes. They identified index cases and family members with microsatellite-stable tumors and germline substitutions in the exonuclease-active sites of POLD1 (c.1433G > A (p.Ser478Asn)) and POLE (c.1270C > G (p.Leu424Val)). Analysis indicated that the aminoacid substitutions would perturb normal polymerase proofreading activity, thus reducing the capacity to correct mispaired bases that are erroneously inserted during DNA replication, thereby accelerating the accumulation of somatic genetic changes in cells. Tumors from these patients exhibited an ultramutant tumor phenotype, consistent with the molecular signature of tumors with somatically acquired variants in the exonuclease domain of POLE. The germline POLD1 variant c.1433G $>$ A (p.Ser478Asn) was associated with endometrial cancer, as it was identified in two families with multiple cases of endometrial cancer diagnosed between 33 and 52 years. In total, seven women had endometrial cancer: four were heterozygous for c.1433G > A (p.Ser478Asn), one was an obligate variant carrier, and two had not been genotyped. Genotyping for c.1433G $>$ A (p.Ser478Asn) was then performed for 386 unselected endometrial cancer cases without a reported family history of CRC, but no carriers were detected in this cohort. The germline POLE variant c.1270C $>$ G (p.Leu424Val) was identified in 13 probands with multiple adenomas and CRC. Interestingly, there were no extracolonic tumors reported in the probands or their family members.

Subsequently, Valle et $a l^{40}$ studied a Spanish cohort comprising 858 familial and early-onset CRC cases using a combination of variant-specific genotyping (for POLE c.1270C $>$ G (p.Leu424Val), and POLD1 c.1433G > A (p.Ser478Asn)) and, in a subset, limited exon sequencing. A novel POLD1 exonuclease domain variant (c.1421 T $>$ C (p.Leu474Pro)) was identified in a family with endometrial, colorectal cancer, brain, gastric, and bladder cancer. One woman heterozygous for the variant and her obligate 
carrier sister had developed endometrial cancer in their $50 \mathrm{~s}$. Consistent with previously identified POLD1 families, a colon tumor and an endometrial tumor from two separate individuals in this family were MMR proficient.

Rohlin et $a{ }^{41}$ sequenced the exomes of several members of a large family with a dominant family history of MMR-proficient cancer that included endometrial, colorectal, ovarian, pancreatic, brain, and gastric cancer. They took an agnostic approach to converge on a novel POLE exonuclease domain variant (c.1089C $>$ A (p.Asn363Lys)) as the cause of the cancers in this family. Two women, both heterozygous for the variant, developed endometrial cancer and another malignancy; one developed endometrial and ovarian cancer at the age of 45 years, and the other developed colorectal cancer at the age of 43 years followed by endometrial and ovarian cancer at the age of 50 years.

Elsayed et $a{ }^{42}$ genotyped a Dutch cohort comprising 1188 familial CRC and polyposis cases for POLE c.1421 T >C (p.Leu424Val) and POLD1 c.1433G > A (p.Ser478Asn). Three index cases were identified to have POLE c.1421 T >C (p.Leu424Val). One case was a woman who developed a cecal tumor, colon polyps, and endometrial cancer. The endometrial tumor was MMR proficient, but the cecal tumor showed loss of MSH6 protein expression and MSI, which is characteristic of a germline defect in MSH6. Cecal tumor DNA sequencing revealed a hypermutator phenotype and two pathogenic somatic mutations in MSH6, thus explaining the immunohistochemical and molecular characteristics of the tumor. This suggests that the increased rate of somatic genetic variant accumulation resulting from compromised polymerase proofreading could, at times, precipitate concomitant biallelic somatic loss of an MMR gene, which would thereby initiate MMR-deficient tumorigenesis. This hypothesis is supported, at least for endometrial cancer, by a study of 544 endometrial tumors, which showed that $P O L E$ somatic exonuclease domain variants occur with equal frequency in microsatellite-stable and -unstable tumors (5.9\% and 5.2\%, respectively), and that POLE variants can be concomitant with somatic genetic variant in MMR genes in a subset of MSI tumors. ${ }^{43}$ Therefore, individuals with a pathogenic germline variant in POLD1 or POLE can present with both microsatellite-stable and -unstable endometrial tumor phenotypes.

Subsequently, Spier et al ${ }^{44}$ screened POLE and seven other polymerase genes in 266 German patients with multiple colorectal adenomas or Amsterdam criteria-positive family history, and for whom no causative germline alteration in $A P C$, MUTYH, or MMR genes had been identified. ${ }^{44}$ The POLE c.1421 T>C (p.Leu424Val) variant was identified in $1.5 \%$ of all cases, increasing to $4 \%$ for familial cases, and $7 \%$ for familial polyposis cases specifically. An additional nine putative pathogenic POLE variants were identified. While no endometrial cancer cases were reported in $P O L E$-positive individuals, a range of other tumors and diseases were, including ovarian cancer at the age of 33 years. With regard to the variants in other polymerase genes reported as potentially pathogenic, the POLD3 variant c.1154G > A (p.Arg385His) was identified in one proband from an Amsterdam-positive family, and his endometrial cancer-affected mother. Further study of POLD3 may be of interest with respect to endometrial cancer, but the detection of this variant in control populations at frequency $0.1 \%$ suggests that it is unlikely to be proven to be associated with a high risk of cancer.

Most recently, Bellido et al ${ }^{45}$ presented data for pathogenic variants identified in the exonuclease domain of POLE and POLD1 in 529 kindreds, 444 with familial non-polyposis colorectal cancer, and 88 with polyposis, a review of existing and newly generated data. Four POLD1 variants with strong evidence of pathogenicity were identified in nonpolyposis colorectal cancer families: c.946G $>\mathrm{C}$ (p. Asp316His); c.947A > G (p.Asp316Gly); c.1225C > T (p.Arg409Trp); and c.1421 T>C (p.Leu474Pro). Of note, endometrial cancer at the age of 36 and 57 years was reported in two carriers of the c.947A $>\mathrm{G}$ (p.Asp316Gly) variant. Further the phenotypic spectrum of $P O L E / P O L D 1$-associated spectrum was widened to include brain tumors.

Taken together, these reports support the hypothesis that pathogenic germline variants in the exonuclease proofreading domains of POLE (exons 9-14) and POLD1 (exons 8-13) that are deleterious to polymerase proofreading function predispose to endometrial cancer. To date, three likely pathogenic POLD1 variants (c.947A $>$ G (p.Asp316Gly); c.1433G > A (p.Ser478Asn); c.1421 T > C (p.Leu474Pro)) have been identified in nine women with endometrial cancer (proven or obligate carriers) from four families, and two likely pathogenic POLE variants (c.1421 T>C (p.Leu424Val); c.1089C >A (p.Asn363Lys)) in three endometrial cancer patients from two families.

However, because of the paucity of reports so far, and the fact that all studies to date have focused on ascertainment via probands with polyposis and/or colorectal cancer, the POLD1- and POLE-associated endometrial cancer risks are yet to be estimated. Similarly, little is known about prognosis for germline pathogenic variant carriers, but somatic POLE proofreading variants appear to predict favorable endometrial cancer prognosis. ${ }^{46}$ It was initially suggested that, as an intermediate measure, the clinical management of Lynch syndrome and MUTYH-associated polyposis patients should be integrated for the management of these patients, with regular and frequent colonoscopic polypectomy and consideration of risk-reducing surgery. ${ }^{39}$ Although the absolute cancer risks associated with (presumed) pathogenic variants in POLD1 and POLE are not established, preliminary clinical management recommendations have since been published 
as part of the comprehensive review by Bellido et al,45 namely: colonoscopy every $1-2$ years and gastroduodenoscopy every 3 years, starting at the age of 20-25 years (re-evaluate periodicity according to the findings), adding endometrial cancer screening beginning at the age of 40 years for POLD1 female carriers.

This same review also published preliminary recommendations for genetic testing. ${ }^{45}$ Given the overlapping phenotypes of POLD1/POLE with Lynch syndrome and attenuated adenomatous polyposis (APC/MUTYH), the clinical criteria for hereditary non-polyposis CRC (revised Bethesda) were adapted to the attenuated or oligopolyposis scenario, and additional specific $P O L E / P O L D 1$ characteristics were taken into consideration. It was suggested that POLD1 clinical genetic testing of endometrial cancer patients may be considered in the context of a strong family history of colorectal or endometrial cancer (two or more relatives) or a single relative with colorectal cancer $<60$ years or endometrial cancer $<60$ years. ${ }^{45}$ Extrapolating from these recommendations, POLD1 and POLE testing of unselected endometrial cancer patients should be limited to the research setting, as should POLE testing of endometrial cancer patients identified in the familial cancer setting.

\section{PTEN}

The PTEN gene is a tumor suppressor that encodes a protein that has a crucial role in the control of the PI3K/AKT and MAPK pathways. Frequent somatic genetic inactivation of PTEN occurs in endometrial cancer, as is the case for many other tumor types. During tumor development, loss of the PTEN protein leads to increased cell proliferation and reduced cell death. Haploinsufficiency in mice $\left(p t e n^{+/-}\right)$causes the mice to develop a range of tumors, with endometrial hyperplasia and endometrial cancer being frequent. ${ }^{47}$

Germline variants that cause loss of PTEN function cause an inherited predisposition to multiple cancers. Cowden syndrome is a PTEN hamartoma tumor syndrome characterized by multiple benign hamartomas-typically on the skin, mucous membranes, and the intestine-and a susceptibility to thyroid, breast, and endometrial cancer in particular. ${ }^{48-50}$ Increased risk of renal cancer, colorectal cancer, and melanoma have also been reported. ${ }^{48-50}$ The reported lifetime risk of endometrial cancer to age 70 years ranges from $19 \%(10-32 \%)^{50}$ to $28 \%$ (17-39\%.48 The PTEN-related endometrial cancer risk is expected to significantly increase from age 25 years, ${ }^{48}$ but reports of adolescent onset endometrial cancer in the context of a personal and/or family history of Cowden syndrome have been attributed to pathogenic germline variants in this gene. ${ }^{51-53}$ Endometrioid histology is reported to be the most prevalent histologic type in individuals who carry a PTEN pathogenic variant. ${ }^{54}$
Genetic predisposition to endometrial cancer outside of a clinical Cowden syndrome context appears to be uncommon. Germline PTEN screening of a population-based cohort of 240 women with endometrial cancer did not identify any pathogenic variants, suggesting that they do not account for a significant proportion of endometrial carcinoma at the population level, ${ }^{55}$ and it is notable that only a single PTEN pathogenic variant was identified across three different studies reporting results of multigene cancer panel testing of unselected ${ }^{56}$ or familial ${ }^{57,58}$ endometrial cancer patients, and this patient carrying this variant reported a clinical history consistent with Cowden syndrome. ${ }^{56}$ Nevertheless, identifying PTEN-related endometrial cancers is important because of the increased risks of other cancers and the implications for family members. Published clinical management guidelines ${ }^{59}$ recommend endo- $^{-}$ metrial screening starting at the age of 30 years by annual endometrial biopsy or transvaginal ultrasound, annual mammogram, annual examination of the thyroid, 2-yearly renal imaging, 2-yearly colonoscopy and annual dermatologic examination, and risk-reducing mastectomy may also be recommended for young women with dense breasts or indications for repeated biopsies. ${ }^{60}$

Endometrial cancer is a major diagnostic criterion of Cowden syndrome. It is included in the strict international Cowden Consortium operational diagnostic criteria originally established to identify PTEN pathogenic variant carriers, and the more relaxed Cleveland Clinic Score (CC Score) system developed to identify individuals with clinical features reminiscent of Cowden syndrome (termed Cowden-like syndrome) and $>3 \%$ probability of carrying a PTEN pathogenic variant. ${ }^{61}$ However, additional factors appear to have utility for identifying endometrial cancer patients with a germline PTEN pathogenic variant; analysis of 371 prospectively enrolled endometrial cancer patients showed that the clinical features predicting germline PTEN-related endometrial cancer are early age of onset (50 years or less), endometrioid histologic subtype, macrocephaly, a high a priori risk of Cowden syndrome (CC Score 29 or greater), synchronous renal cell carcinoma, and low PTEN tumor protein expression. ${ }^{54}$ Clinical testing of PTEN is thus advisable for endometrial cancer patients with features or family history indicative of Cowden syndrome, and should be considered when endometrial cancer is diagnosed in adolescence. However, current evidence suggests that testing of 'population-based' endometrial cancer patients for germline pathogenic variant in PTEN should preferably be undertaken in the research setting only.

\section{BRCA1 and BRCA2}

Pathogenic variants in $B R C A 1 / 2$ that lead to protein truncation or instability, or that disrupt the function 
of important protein domains, predispose to breast, ovarian, and other cancers. In addition to several case-reports, ${ }^{62,63}$ multiple studies have been undertaken to investigate the risk of endometrial cancer attributed to BRCA1/2 pathogenic variants, and others have screened endometrial cancer patients (purportedly familial or unselected) using multigene cancer panels that included BRCA1 and BRCA2. The design of and evidence from these studies (23 total, 17 non-overlapping) is summarized in Supplementary Table 1. Unfortunately, despite active research on this topic, the published evidence remains conflicting; most studies report evidence based on a relatively small number of proven carriers with endometrial/uterine cancer, comparison with appropriate control/reference groups is lacking for panel gene studies, and assessment of the evidence is further complicated by the fact that tamoxifen use for treatment or prevention of breast cancer is known to lead to an increased risk of endometrial cancer.

Three non-overlapping studies have provided evidence that tamoxifen use is associated with increased endometrial cancer risk in BRCA1 pathogenic variant carriers. Segev et al ${ }^{64}$ prospectively followed 4456 women with a $B R C A 1 / 2$ pathogenic variant, with mean follow-up of 5.7 years. Endometrial cancer was reported for 17 women; 8 of these had received tamoxifen, translating to an RR of 4.1 (1.9-7.87; $P=0.001$ ) for this subgroup, compared with a modest nonsignificant increased risk for women who had not received tamoxifen (RR 1.7 (0.8-3.1); $P=0.1$ ). Similarly, analysis of 1203 highrisk breast/ovarian cancer families screened for pathogenic variants in $B R C A 1$ and $B R C A 2^{65}$ showed that tamoxifen therapy was significantly associated with endometrial cancer risk in $B R C A 1 / 2$ families (HR 6.7 (3.1-15.2)), while endometrial cancer risk was marginally, but not significantly, greater than unity for pathogenic variant carriers compared with non-carrier family members (BRCA1 HR 1.3 (0.7-2.4); BRCA2 HR 1.1 (0.5-2.5)). Another recent study comparing observed and expected rates for serous/serous-like endometrial cancer in BRCA carriers $^{66}$ provides support for association of risk of aggressive endometrial cancer subtypes with tamoxifen exposure in BRCA1/2 carriers (observed: expected (O:E) rate 24.4 (5.0-71.3), $P<0.001)$. Further, a case-control study comparing risk factors among $B R C A 1 / 2$ carriers has reported endometrial cancer risk of 3.5-fold (1.5-8.1) associated with tamoxifen use. ${ }^{67}$ These estimates of endometrial cancer risk with tamoxifen use among carriers are generally consistent with the consensus RR of 2.4 (1.5-4.0) reported from meta-analysis of five randomized breast cancer prevention trials, ${ }^{68}$ although it should be noted that estimates from long-term follow-up of the IBIS-I trial alone indicate that risk of endometrial cancer is significantly increased during active treatment only, reducing from 3.8-fold risk in years $0-5$ to $1.5(0.8-2.7)$ after a median 16 years follow-up. ${ }^{69}$
Three recent multigene panel studies did not specifically assess risk associated with BRCA1/2 carrier status, but do provide measures of the frequency of $B R C A 1 / 2$ pathogenic variants in endometrial cancer patients, ranging from $0.5 \%$ in unselected cases ${ }^{56}$ up to $1.4 \%$ in those referred for genetic testing by clinicians. ${ }^{57,58}$ None of these three studies provided information on tamoxifen use. Of the other 15 non-overlapping studies investigating association of carrier status with development of endometrial/uterine cancer, seven reported evidence supporting at least modest increased risk of endometrial cancer for carriers of a pathogenic variant in $B R C A 1$ or BRCA2. Tamoxifen use was recorded for only three of these, and it is possible that some endometrial cancer patients received adjuvant tamoxifen therapy for previous breast cancer. However, tamoxifen use is less likely to be confounding the interpretation of results for studies that included patients with first primary endometrial cancer diagnosed before 1990, the initiation of tamoxifen chemoprevention trials. Results reporting analysis that reached statistical significance were noted for only 3/15 studies. The largest study to date, analysis of 11847 BRCA1 pathogenic variant carriers from across Europe and North America, observed a statistically significant increased risk of endometrial cancer (RR $2.7 \quad(1.7-4.2 ; \quad P<0.001),{ }^{70}$ which remained similar when restricting analysis to women unaffected with breast cancer $(\mathrm{RR}=3.1 \quad(1.7-5.7$; $P<0.001)$ to restrict the confounding effects of tamoxifen on endometrial cancer risk. Excess risk of endometrial cancer was also reported for relatives of 57 Ashkenazi ovarian cancer-affected BRCA1 carriers (RR 9.4, $P=0.0003$ ), a result based on only four events. ${ }^{71}$ Most recently, a prospective study of $1083 B R C A 1 / 2$ carriers after risk-reducing salpingooophorectomy ${ }^{66}$ reported significantly increased risk of serous/serous-like endometrial cancers in $B R C A 1 / 2$ carriers overall (O:E ratio 14.8 (4.8-34.6), $P<0.001$ ), but no significant risk of endometrioid subtype cancer (O:E ratio $0.6(0.1-2.0), P=0.88)$. Moreover, significantly increased risk of serous/like cancer was limited to BRCA1 carriers specifically (O:E ratio $22.2(6.1-56.9), P<0.001) .{ }^{66}$ The same study reported evidence for increased risk of serous/ serous-like cancer with and without tamoxifen exposure, presented only for $B R C A 1 / 2$ carriers combined. Another recent smaller study assessing occult and subsequent cancer incidence following risk-reducing salpingo-oophorectomy identified a single endometrioid subtype cancer in a BRCA1 carrier at surgery, and authors concluded that they cannot endorse concurrent hysterectomy for cancer risk reduction. ${ }^{72}$ Another four studies (sample sizes 31-151) have investigated if $B R C A 1 / 2$ pathogenic variants may increase risk of endometrial cancer of serous subtype specifically, with three of these ${ }^{73-75}$ providing largely observational evidence that serous subtype endometrial cancer may be part of the $B R C A 1 / 2$ spectrum. However, it is also clear from 
studies of unselected endometrial cancer patients where information on histological subtype was available that carriers of a BRCA1 or BRCA2 pathogenic variant mostly present with endometrioid subtype endometrial cancer, even in women exposed to tamoxifen. $56,64,65,76-78$

Considering findings across all studies, results could be interpreted to suggest that endometrial cancer may be more likely to develop in BRCA1 carriers compared with BRCA2 carriers. The statistically significant associations noted above were observed for BRCA1 carriers only, and in most of the more observational studies, endometrial canceraffected patients appeared more often to carry a pathogenic variant in BRCA1 compared with BRCA2. ${ }^{64,65,73-76,79}$ Only one study comparing risk by subtype has provided evidence that the significant increase in endometrial cancer risk for BRCA1 carriers is for serous/serous-like cancers only, ${ }^{66}$ and on this basis has advocated that advantages and risks of hysterectomy should be discussed with BRCA1 carriers at the time of considering risk-reducing salpingo-oophorectomy.

All the evidence taken together indicates that $B R C A 1 / 2$ pathogenic variant carriers have an increased risk of endometrioid and non-endometrioid endometrial cancer after tamoxifen treatment that is at least comparable to that observed for noncarriers in the general population, and there is suggestive evidence for a modest increased endometrial cancer risk in the absence of tamoxifen exposure, in particular for BRCA1 carriers. Largerscale testing of these genes in endometrial cancer patients is necessary to generate information to clarify risk of endometrial cancer subtypes associated with carriage of BRCA1 or BRCA2 pathogenic variants. However, given that there are wellestablished clinical management protocols in place for BRCA1 and BRCA2 pathogenic variant carriers, it could be argued that there is value in including these genes on an endometrial cancer panel for both research purposes and report back of actionable incidental findings.

\section{TP53}

The TP53 tumor suppressor gene encodes 12 different p53 isoform proteins, ${ }^{80}$ which are involved in many anticancer processes, such as DNA repair, cell cycle control, apoptosis, and inhibition of angiogenesis. TP53 inactivation is a common somatic event during endometrial cancer development, with TP53 somatic variants being significantly more frequent in uterine serous tumors. ${ }^{4}$ Pathogenic germline variants in TP53 cause Li-Fraumeni syndrome (LFS), a cancer predisposition syndrome characterized by sarcomas (including endometrial leiomyosarcoma), breast cancer, brain cancer, adrenocortical carcinoma, hematopoietic, and other malignancies.
Endometrial cancer (non-sarcomatous) is not a known manifestation of LFS, $^{81}$ but it has been observed in TP53 pathogenic variant carriers with a younger age of onset than what is expected in the population.82,83 Pennington et al $^{75}$ assessed 151 uterine serous papillary carcinoma patients and identified two patients with a germline TP53 missense variant that were considered clinically significant since both had been reported as the causal variants in patients with LFS. Family history assessment was only possible for one variant carrier, but the cancer history was not suggestive of LFS (although family history may be lacking in LFS because of de novo germline alteration). Using a multigene panel test to simultaneously sequence 150 genes associated with hereditary cancer, Heitzer et $a l^{84}$ tested a woman who presented with bilateral breast cancer, aged 38 and 44 years, and endometrial cancer aged 43 years with a significant family history of breast, brain, and gastric cancer. Pathogenic germline variants were identified in two high-penetrance genes, TP53 and CDH1, explaining the diverse cancers in this patient and the family. The authors proposed that the endometrial, brain, and ductal breast cancer developed as a result of the TP53 variant and the gastric and lobular breast cancer developed from the CDH1 variant. Recently, Chao et $a l^{85}$ describe a pathogenic TP53 missense variant in a LFS-like patient with endometrial cancer coexisting with peritoneal malignant mesothelioma at the age of 54 years. However, no TP53 pathogenic variants were identified in gene cancer panel testing of 381 unselected $^{56}$ or of a total of 745 clinician-referred familial ${ }^{57,58}$ endometrial cancer patients. In summary, there is limited information to suggest that TP53 pathogenic variants may be associated with increased endometrial cancer risk.

Predisposition of TP53 pathogenic variant carriers to multiorgan tumorigenesis presents a specific challenge for cancer risk management programs. There is some evidence from human studies and mouse models to suggest that use of radiotherapy may be contraindicated for cancer treatment (reviewed in McBride et $\left.a l^{86}\right)$. Published reports indicate possible benefit of neonatal and annual whole-body magnetic resonance imaging (MRI) surveillance, ${ }^{87-89}$ and regular biochemical surveillance, ${ }^{88}$ with detection of lesions at early stage. However, there is currently no international consensus on the components of a cancer screening program for TP53 pathogenic variant carriers, and there is great variation in guidance for carriers across institutions, regions and countriesranging from no action to comprehensive surveillance schedules being evaluated in a clinical trial setting at selected centers. ${ }^{86}$

Given the complexities of counseling and clinical management of TP53 variant carriers, even within the context of LFS, it is recommended that large-scale research studies be undertaken to establish the level of endometrial cancer risk, if any, associated with 
pathogenic variants in TP53, before consideration of TP53 in clinical testing for endometrial cancer diagnosis. Further, it should be acknowledged that most pathogenic TP53 variants identified in the context of LFS are missense substitutions, ${ }^{90}$ so assigning TP53 variant pathogenicity for novel missense alterations will be particularly problematic for the analysis of a non-syndromic cancer. Thus, screening TP53 in endometrial cancer patients identified both inside and outside of a LFS context will be useful for research purposes.

\section{CHEK2}

The CHEK2 gene is a tumor suppressor that encodes a checkpoint kinase that participates in various cell processes, including cell cycle regulation, DNA repair, and apoptosis. Rare variants in this gene have been reported to be associated with moderately increased risks of cancer. The missense substitution c.470 T>C (p.Ile157Thr) has been reported be associated with a 1.4-fold increased risk of breast cancer, ${ }^{91,92}$ and a 1.7-fold increased risk of colorectal cancer. ${ }^{93}$ In addition, CHEK2 c.349 A > G (p.Arg117Gly), c.538C $>$ T (p.Arg180Cys), and c.1036C $>$ T (p.Arg346Cys) was reported to be associated with increased risk of breast cancer (ranging from 1.3- to 5.1-fold), whereas c.1312G $>\mathrm{T}$ (p.Asp438Tyr) and c.1343 T $>$ G (p.Ile448Ser) were associated with a 2.2- to 3.0-fold risk of prostate cancer. ${ }^{94}$ Most notably, CHEK2 c.1100delC (p.Thr367Metfs*15), a founder variant in several European countries with carrier frequencies between 0.5 and $1 \%$, has been convincingly shown to be associated with an $\sim 2.3$ fold increased risk of breast cancer for women. ${ }^{95-97}$ Consistent with these risk estimates from large-scale studies, segregation with disease is incomplete in families, ${ }^{95}$ although it was observed at somewhat increased frequency of $5.1 \%$ in the initial study of breast cancer index cases with a family history of breast cancer, ${ }^{95}$ and there is evidence for overrepresentation of the variant in cases enriched for family history. ${ }^{97}$ Recently, a large-scale cohort study of 86975 individuals from the Copenhagen region provided evidence that risk of multiple cancer types are associated with the c.1100delC variant; ${ }^{98}$ the risks reported were 2.08-fold risk for breast cancer, and 1.45-fold for other cancer types combined. Considered individually, statistically significant associations were observed for cancers of the stomach, kidney, and prostate, although confidence intervals were wide. The risk estimate reported for uterine cancer in this study was 1.70 (0.70-4.14).

There have been a limited number of studies assessing the role of germline CHEK2 variation in endometrial cancer specifically. A study supporting a link of endometrial cancer with CHEK2 was a study of 629 colorectal cancer patients from the Netherlands which showed that c.1100delC
(p.Thr367Metfs*15) was more likely to be observed in those that reported a family history of colorectal or endometrial cancer than in sporadic endometrial cancer patients. ${ }^{99}$ This observation was not replicated in a Swedish case-control study of 705 endometrial cancer cases (all subtypes) and 1565 controls, which found that CHEK2 c.1100delC had no association with endometrial cancer risk. ${ }^{100}$ Konstantinova et al ${ }^{101}$ showed that CHEK2 c.470 $\mathrm{T}>\mathrm{C}$ (p.Ile157Thr) was not associated with endometrial cancer when they compared 268 unselected endometrial cancer patients to 449 female controls from Bulgaria. In fact, the variant was observed more frequently in controls than in patients $(2.45 \%$ vs $1.75 \%$ respectively) and showed no association with histological subtype, after being identified in individuals with endometrioid, mucinous, and clear-cell histologies. A Polish case-control study of four founder alleles in the CHEK2 gene (c.1100delC (p.Thr367Metfs*15); c.470 T $>$ C $\quad$ (p.Ile157Thr); c.909_1095del (p.Met304Leufs*16), reported as del ex9-10; c.444+1G > A) assessed colorectal and endometrial cancer risk from the analysis of 5496 unaffected controls, 1085 unselected colorectal cancer cases, 303 unselected endometrial cancer cases, and 463 colorectal or endometrial cancer probands reporting at least two cases of Lynch syndromeassociated cancer in first-degree relatives. Colorectal cancer risk was 2.5-fold increased for familial MMRproficient cancer and unselected carriers of the c.470 T $>$ C (p.Ile157Thr) variant, with no evidence for increased endometrial cancer risk in familial or unselected patients who tested negative for pathogenic variants in MLH1, MSH2, and MSH6. ${ }^{102}$ Assessment of 151 uterine serous carcinoma patients based in the USA ${ }^{75}$ using a panel-based testing strategy identified two patients with mixed histology with either the germline CHEK2 variant c.470 T >C (p.Ile157Thr) $(0.7 \%)$ or c.1100delC $(0.7 \%)$. Three other US-based multigene panel testing studies of endometrial cancer patients unselected for histological subtype have also identified CHEK2 variants in probands, with frequencies of $0.3 \%$ (1/292, subtype unknown; variant nomenclature not specified) in patients with clinical features of Lynch syndrome ${ }^{58}$ ), $1.0 \% \quad 4 / 381,3$ endometrioid and 1 clear-cell subtype; all carrying c.1100delC) in unselected patients, ${ }^{56}$ and $1.1 \%(5 / 453)$ in patients referred for genetic testing (subtype unknown). ${ }^{57}$ The latter study, ${ }^{57}$ reported 4/5 CHEK2 variants as Pathogenic (c.433C > T (p.Arg145Trp), c.507delT (p.Phe169LeufsX2), c.1100delC (p.Thr367MetfsX15), c.1283C $>$ T (p.Ser428Phe)), and the other as Expected Pathogenic (c.470 T $>$ C (p.Ile157Thr).

In summary, evidence exists to support increased risk of cancers of the breast, colorectum, and possibly stomach, kidney, and prostate for the CHEK2 c.1100delC loss-of-function variant, a finding that might be inferred to extend to other loss-offunction variants. However, the evidence based on limited data does not support association of CHEK2 
variants with markedly increased risk of endometrial cancer, nor inclusion of this gene on an endometrial cancer-focused panel for clinical testing. It is relevant to note, although, that clinical testing of CHEK2 c.1100delC variant has been introduced in the Netherlands for women with personal/family history of breast cancer referred for BRCA1/2 testing and genetic counseling, and specific clinical management protocols including more intensive surveillance. For these and other clinical testing sites adopting such a stance, there may be an advantage to masked testing of CHEK2 for endometrial cancer patients, with report back of the CHEK2 c.1100delC variant as an actionable incidental finding only for those patients considered eligible for CHEK2 testing due to their personal or family history of breast cancer.

\section{MUTYH}

The MUTYH gene product is part of the base excision repair system, which repairs oxidative damage to DNA. MUTYH-associated polyposis is an autosomal recessively inherited predisposition to adenomatous polyposis and colorectal cancer. From the most comprehensive study to date, the cumulative colorectal cancer risk to age 70 years for biallelic carriers is reported to be $75 \%$ (41-97\%) for males and $72 \%(44-92 \%)$ for females, and for monoallelic carriers it is estimated to be $7 \%(5-11 \%)$ for males and 6\% (4-9\%) for females. ${ }^{103}$ Data from 276 cases from 181 unrelated families provided evidence for significantly increased risk of cancers of the duodenum, ovary, bladder, and skin, ${ }^{104}$ although confidence intervals on these estimates were very wide. The SIR reported for endometrial was 4.6 (0.6-16.5), based on only two reports in the data set. ${ }^{104}$ Win et $a 1^{105}$ observed elevated cancer incidences in 2179 individuals estimated to be monoallelic MUTYH pathogenic variant carriers. The incidence of endometrial cancer in this cohort was 2.3 (1.2-5.1), giving a cumulative risk to age 70 years of $4 \%(2-8 \%)$. In an updated analysis of the same cohort, monoallelic carriers showed increased risk for gastric cancer (HR 9.3 (6.7-13)), hepatobiliary cancer (HR 4.5 (2.7-7.5)), endometrial cancer (HR 2.1 (1.1-3.9), and breast cancer (HR 1.4 (1.0-2.0)).

Barnetson et al ${ }^{106}$ assessed 225 unselected endometrial cancer patients for two common pathogenic MUTYH missense variants (reported in this study as Y165C and G382N; Human Genome Variation Society (HGVS) nomenclature to the common transcript NM_001128425.1: c.536A>G (p.Tyr179Cys), and c.1187G $>$ A (p.Gly396Asp)) and analyzed the entire coding region if only one variant was identified. A single patient with endometrioid adenocarcinoma and a sebaceous carcinoma carried both pathogenic variants; five patients carried a single variant, a frequency was not significantly different to that found in unaffected controls from the same population. Tricarico et al ${ }^{107}$ have since reported two additional endometrial cancer patients with biallelic MUTYH pathogenic variants, as have Vogt et $a^{104}$ as noted above. In contrast, Ashton et al ${ }^{108}$ genotyped 213 endometrial cancer patients and 226 controls for the two common missense variants and identified no biallelic carriers, and the genotype frequencies of the monoallelic carriers were not significantly different from the controls. One US-based multigene panel study did not identify any MUTYH variants in 381 unselected endometrial cancer patients ${ }^{56}$ in patients, but two other US-based studies of 292 (ref. 58) and 453 (ref. 57) clinician-referred patients found $0.1-0.7 \%$ of endometrial cancer patients to be monoallelic carriers of MUTYH variants reported as Pathogenic (including c.536A $>\mathrm{G}$ (p.Tyr179Cys), c.545G $>\mathrm{A}$ (p.Arg182His), c.1145G > A (p.Gly382Asp), с.1185_ 1186dupGG (p.Glu396GlyfsX43)).

In summary, monoallelic carriers of MUTYH variant predisposing to colonic cancers may have a small increased risk of extracolonic cancers. Currently, evidence that monoallelic MUTYH carriers may be at a twofold risk of endometrial cancer is derived from essentially a single study, and confidence intervals on this estimate range from 1.1 to 3.9. Given the paucity of cases so far, it is not possible to ascertain an estimate of endometrial cancer risk for biallelic carriers. While some local diagnostic policies may recommend including genes on a panel if evidence supports a minimum of a twofold increased risk for the cancer being targeted, it is likely that the imprecision in risk estimates for endometrial cancer risks would prevent adoption of MUTYH on an endometrial cancerfocused clinical testing panel. However, as noted for CHEK2 above, clinical management implications for other cancers may drive testing and selected reporting of this variant in endometrial cancer cases. Namely, current management recommendations for biallelic MUTYH carriers focus on the risk of colon cancer, and include colonoscopy every 2 years starting at the age of 18-20 years. Most patients are managed conservatively with polypectomy to remove adenomas, with surgery indicated if there are large numbers of adenomas. ${ }^{38,104}$ Usually no additional cancer screening is recommended in monoallelic MUTYH carriers pathogenic variant carriers; the National Comprehensive Cancer Network (https://www.nccn.org) guidelines recommendation for colonoscopy for mono-allelic MUTYH carriers is limited to only carrier individuals identified after presenting with personal history of adenomas or meeting guidelines for serrated polyposis syndrome i.e. management is defined by individual risk assessment. Thus, research testing with intent to report back results for the subset of endometrial cancer patients with personal or family history of polyposis or colorectal cancer may be considered appropriate by some test providers. 


\section{STK11}

STK11 (also known as $L K B 1$ ) is a tumor suppressor gene that is responsible for Peutz-Jeghers syndrome (PJS), which is a rare autosomal dominant disease that is characterized by gastrointestinal hamartomatous polyposis and mucocutaneous melanin spots. Individuals with PJS are at increased risk for a range of epithelial malignancies (colorectal, gastric, pancreatic, breast, and ovarian cancers), and rare cancers such as adenoma malignum of the cervix. ${ }^{109}$ A metaanalysis of 104 women with PJS revealed that two PJS patients had developed endometrial cancer $(R R=16,95 \% C I=1.9-56)$, giving a cumulative risk from age 15 to 64 years of $9 \% .{ }^{110}$ It would appear that STK11 loss-of-function variants are very rare; only a single pathogenic STK11 variant was identified across four different multigene panel testing studies of endometrial cancer patients ${ }^{56-58,75}$ —and it is notable that the variant occurred in trans with a deleterious MSH6 variant in a 1/292 endometrial cancer patients with clinical features of Lynch syndrome. ${ }^{58}$ Based on these observations, STK11 testing may be appropriate for individuals from family with features of PJS syndrome, where there are implications for family management including extensive cancer surveillance recommendations ${ }^{111}$ and family planning. However, there is no precise estimate of endometrial cancer risk, and inclusion in an endometrial cancer-focused panel should be considered for research purposes only.

\section{Genes implicated in endometrial cancer for patients presenting as part of Cowden-like syndrome: SDHB, SDHC, SDHD, AKT1, PIK3CA, KLLN, and SEC23B}

PTEN germline pathogenic variants are identified in only $5 \%$ of patients with features indicative of Cowden-like syndrome, which has led to investigation of other genetic causes of disease in these individuals. Germline variation in a number of genes has been reported as implicated in predisposition to cancer in Cowden-like families, namely the succinate dehyrogenase genes $S D H B, S D H C, S D H D,{ }^{54,112-114}$ and the $A K T 1$ and PIK3CA genes, which lie downstream of PTEN and act in the same molecular pathway. ${ }^{115}$

In initial studies, the standardized incidence rate of thyroid cancer was reported to be $63 \%(42-92 \%)$ for carriers of SDHx variants and 45\% (26-73\%) for KLLN 'epimutations', 113 and inheritance of germline SDHx variants was implicated as causal for breast, renal and endometrial cancer in relatives of thyroid cancer patients. ${ }^{112}$ However, more recent studies have shown that the frequency of $S D H B-D$ variants is similar in cancer-affected probands with and without a germline pathogenic variant in PTEN. $S D H B-D$ variants were identified in $8 \%$ of thyroid/ breast/renal patients without PTEN pathogenic vari- ants, vs $6 \%$ of those with a PTEN pathogenic variant $(P=0.2) .{ }^{60}$ Similarly, germline missense alterations in $S D H B-D$ were identified in $37 / 367(10 \%)$ of endometrial cancer patients, two of whom also carried germline pathogenic variants in PTEN, and there was no difference in frequency of germline $S D H B-D$ variants in PTEN carriers vs non-carriers $(P=0.9) .{ }^{54}$ This has led to the suggestion ${ }^{54,60}$ that variants in $S D H B-D$ may act as modifiers of cancer risk, that is, $S D H D-B$ variants are likely not individually associated with a dominantly inherited high risk of cancer. The evidence for involvement of AKT1 and PIK3CA germline variation in Cowdenlike syndrome is from a single study of 91 individuals without germline PTEN pathogenic variants; ${ }^{115}$ variants considered to be deleterious to gene function, on the basis of molecular assays for all variants pooled, were identified in 10/91 individuals (11\%) for PIK3CA (7 missense, 1 nonsense, 2 indels), and 2/91 (2\%) for AKT1 (both missense).

Further, germline promoter methylation of $K L L N$, which lies upstream of PTEN, has been proposed as a cause of inherited cancer in Cowden-like families. ${ }^{54,116}$ Germline $K L L N$ methylation is reported to associate with cancer status in families, ${ }^{116}$ and with reduced expression of KLLN (but not PTEN). That is, the mechanism by which altered $K L L N$ function would predispose to cancer is not directly related to altered function of PTEN. Endometrial cancer patients in Cowdenlike families with $K L L N$ germline methylation have been reported to have earlier age at onset, compared with those without methylation, ${ }^{54}$ but as yet there is no evidence that genetic variation in $K L L N$ is associated with methylation status, or directly with cancer risk.

Most recently, germline variants in SEC23B have been implicated as causal for cancer in Cowden-like families, by whole-exome sequencing of probands, follow-up of candidate pathogenic variants in multigenerational pedigrees, and subsequently in independent series of thyroid cancer patients with Cowden syndrome, and several TCGA cancer data sets. ${ }^{117}$ A SEC23B c.1781 T > G (p.Val594Gly) variant was identified in a single family, including a patient with endometrial cancer at the age of 35 years. Presumed pathogenic SEC23B germline variants were reported to be enriched in TCGA thyroid cancer patients with earlier age at onset (10 unique variants), four unique variants were identified in TCGA breast cancer cases, and three different variants were identified in TCGA endometrial cancer cases. Of the three variants identified in TCGA endometrial cancer cases (c.389 T $>$ C (p.Ile130Thr), c.649C > T (p.Arg217*), c.490G > T (p.Val164Leu)), one overlapped with those reported for breast cancer cases and for thyroid cancer cases. Notably, 16/18 unique variations were missense alterations, predicted to be deleterious on the basis of bioinformatic prediction tools, and 8/18 variants were reported in the general population, albeit at low frequency (minor allele frequency $\leq 0.0075$ ). A comparison of the SEC23B variant frequency in TCGA thyroid 
cancer cases vs population controls, after selecting for the subset of variants with minor allele frequency $\leq 0.0004$, yielded an OR of 2.5 (1.3-4.7). While a similar analysis was not feasible for endometrial cancer (with only two cases eligible), these findings suggest that $S E C 23 B$ variation is unlikely to be associated with a high risk of cancer.

In summary, there is still considerable uncertainty about the clinical significance of variants in the $S D H B-D$ genes, and the relevance of KLLN methylation, with respect to endometrial cancer risk, and it has been publicly recommended that routine testing of these genes should not be conducted in the clinical setting. ${ }^{16}$ In addition, the current limited evidence suggesting a role for germline $A K T 1$ and PIK3CA variants in Cowden-like syndrome has not specifically addressed their relevance to endometrial cancer risk. Variation in SEC23B is unlikely to be associated with high levels of cancer risk. Taken together with some uncertainty about the functional and clinical significance of variants reported in these studies, it would seem premature to investigate variation in any of these proposed Cowden-like genes as causal for familial endometrial cancer outside the research setting. Germline mutations in the $S D H$ genes $(S D H B / D$ in particular) underlie predisposition to hereditary paraganglioma and pheochromocytoma, for which clinical management protocols have been developed, ${ }^{118}$ so report of variation in these genes might be considered appropriate only as incidental findings.

\section{Additional genes reported as implicated in endometrial cancer risk predisposition from directed exome sequencing studies}

Gene discovery approaches have identified three additional genes for which there is suggestive evidence for a role in hereditary endometrial cancer. For all of these genes, there is need to conduct large research studies to determine accurately the level and spectrum of cancer risk with variants considered deleterious to gene function, to inform inclusion of these genes in clinical testing and to define clinical management recommendations for variant carriers.

\section{RINT1}

Exome sequence analysis of early-onset breast cancer patients from multiple-case breast cancer families identified RAD50-interacting 1 (RINT1) as a putative cancer predisposition gene that is associated with breast and Lynch syndrome-spectrum cancers. ${ }^{119}$ One family was identified with a nonsense variant in RINT1 (c.343C > T (p.Gln115*) and included one individual diagnosed with both uterine cancer (age 30 years) and breast cancer (age 49 years) who was heterozygous for this variant. Additionally, comparisons of cancer incidences between the general population and 23 families with rare RINT1 variants (allele frequency $<0.5 \%$ ) deemed to be potentially damaging by in silico prediction models showed an increased incidence of Lynch syndrome cancers in the families of RINT1 variant carriers $(\mathrm{SIR}=3.7$ (1.4-7.7); $P=0.009)$. These rare variants consist of an in-frame deletion, a nonsense variant that truncates six amino acids from the end of the protein, and 21 missense variants. These findings suggested that RINT1 variants that are deleterious to protein function may be associated with predisposition to multiple cancers, including endometrial cancer. However, a recent study evaluating RINT1 in familial breast cancer risk has not provided support for this hypothesis, with no excess of rare truncating and evolutionarily conserved missense variants in 2024 cases vs 1886 controls, and no increased incidence of Lynch syndrome cancers in relatives of RINT1 rare variant carriers. ${ }^{120}$

\section{NTLH1}

The NTLH1 base excision repair gene was recently discovered, also using a whole-exome sequencing approach, to be important in the development of adenomatous polyposis and colorectal cancer. ${ }^{121}$ Homozygous carriage of a germline nonsense alteration was identified in multiple polyposis-affected patients from three unrelated families, with progression to colorectal cancer in at least one family member. Of relevance to this review, all three polyposis-affected women developed an endometrial malignancy (at the age of 57 and 74 years) or premalignancy (at the age of 46 years). Numerous other cancers/tumors were reported in homozygous carriers, including breast cancer (at the age of 56 years), pancreatic cancer (at the age of 47 years), duodenal cancer (at the age of 52 years), and biliary tract hamartoma (at the age of 52 years). The frequency of homozygotes in the total 197 polyposis cases screened was significantly greater than expected $\left(P=7 \times 10^{-8}\right)$, based on the frequency of the risk allele in an in-house data set (0.0036), which was marginally greater than in the ExAC browser (0.0015). These findings suggest that individuals with homozygous loss of function of NTHL1 are at increased risk of adenomatous polyposis, colorectal cancer, and possibly endometrial and other cancers.

\section{FAN1}

The FANCD2/FANC1-associated nuclease 1 (FAN1) gene is a DNA interstrand crosslink repair gene. FAN1 was recently linked to cancer predisposition by whole-exome sequencing of multiple colorectal cancer-affected relatives from a single family meeting the Amsterdam criteria, which identified the nonsense alteration c.141C $>$ A (p.Cys47*) in all three patients tested. ${ }^{122}$ Follow-up testing of 176 additional colorectal cancer families identified three additional likely pathogenic FAN1 variants in $\sim 3 \%$ of families 
with MMR-proficient colorectal cancer and Amsterdam positive family history: a truncating variant c.2854C > T (p.Arg952*), and two missense variants demonstrated to have functional effect in mitomycin assays, c.418G > T (p.Asp140Tyr) and c.1771C > T (p. Arg591Trp). An additional variant c.1018C $>$ T (p. Pro340Ser), untested for function using mitomycin assays, was identified in additional families, with carrier status confirmed for two colorectal cancer patients (aged 40 and 70 years). Additional cancers were reported in these families, including breast cancer (aged 44 years, carrier status confirmed positive; aged 74 years, untested), pancreatic cancer (aged 63 years, untested), GI cancer (untested), and glioma (aged 50 years, untested). Of relevance to this review, early-onset endometrial cancer was reported in the mother and cousin (aged 46 and 42 years) of two brothers carrying the c.2854C $>\mathrm{T}$ (p.Arg952*) variant. However, these individuals (now deceased) were untested for the family variant. FAN1 deficiency, that is, homozygote loss of function, causes milder phenotypes compared with those observed for deficiency in other components of the FA pathway, namely the recessive disease karyomegalic interstitial nephritis, ${ }^{123}$ characterized by slow progressive renal failure that leads to end-stage renal disease before the age of 50 years. So far, early-onset cancer has been reported for two families: rectal adenocarcinoma at the age of 30 years, ${ }^{124}$ and hepatocellular carcinoma at the age of 22 years. ${ }^{125}$ Taken together, these findings suggest that genetic variants deleterious to FAN1 function predispose to colorectal cancer, and possibly other cancers, that may include endometrial cancer.

\section{Additional genes reported as implicated in endometrial cancer predisposition from multigene cancer panel screening studies}

Variation in additional genes has been identified in endometrial cancer patients (unselected or clinicianreferred for testing), by screening using commercial multigene cancer panels, ${ }^{56-58,126}$ Altogether, these include variants in APC (1 truncating), ATM (1 truncating, 2 splice site, 3 missense), BRIP1 (5 truncating), FANCC (1 truncating), NBN (1 truncating), PALB2 (1 truncating), and $R A D 51 C$ (1 truncating, 1 large deletion). We consider these findings from two angles - as an explanation for development of endometrial cancer, or as clinically meaningful incidental findings.

Regarding a possible causal role in endometrial cancer, clinical information extracted from the studies above does not lend strong support for involvement of most of these gene variants in high-risk of endometrial cancer. Only one of these patients reported disease onset under the age of 50 years ( $A P C$, age 28 years), ${ }^{56}$ and four patients reported endometrial cancer in addition to (prior) breast cancer (two ATM (truncating, splice site), FANCC, $P A L B 2),{ }^{57}$ raising the question of possible endometrial cancer development due to tamoxifen use. Second, there is limited evidence for inclusion of most of these genes in cancer panels, and/ or for the level of cancer risk associated with variants reported as pathogenic (including loss-of-function and/or missense alterations in important protein functional domains). Indeed, although BRIP1-truncating variants were initially reported to be associated with a twofold risk of breast cancer from a study of $\sim 1200$ cases and 2000 controls, ${ }^{127}$ the largest study to date ( $>16000$ breast cancer cases, 7300 controls) provides convincing evidence that there is no increased risk of breast cancer associated with truncating variants in BRIP1. ${ }^{128}$ While BRIP1 variation may be associated with risk of other cancers including ovarian cancer, ${ }^{129}$ the findings reported so far are based on relatively small studies and should be interpreted with caution. Only APC would be considered a well-recognized high-risk cancer syndrome gene for which clinical practice guidelines have been established..$^{38}$ On the basis of convincing evidence for risk of breast cancer equivalent to that of truncating variants in BRCA2 for PALB2-truncating variants, ${ }^{130}$ and for a single $A T M$ missense alteration (c.7271 T $>\mathrm{G}$ (p.Val2424Gly)), ${ }^{131}$ clinical management protocols for breast cancer prevention have been put forward for these specific gene alterations. ${ }^{132,133}$ Further, researchers from the Netherlands and United Kingdom have proposed intensified surveillance for breast cancer from 40 to 50 years of age for heterozygous carriers of any ATM loss-of-function variant, based on their meta-analysis of published data estimating RR 3.0 (2.1-4.5) for breast cancer. ${ }^{133}$ However, while clinically meaningful risk association for other specific variants/variant types/genes is not to be discounted, ${ }^{134}$ and a recent paper has presented a framework for counseling of moderate-penetrance cancer-susceptibility variants, ${ }^{135}$ large-scale studies are essential to provide convincing evidence for wider (international) acceptance of their clinical value.

Given this background, apart from the exceptions noted above as relevant for report of incidental findings ( $A P C$ loss-of-function, $P A L B 2$-truncating variants, ATM.7271 T > G (p.Val2424Gly), and possibly ATM loss-of-function variants), it would be inadvisable to interpret variation in the seven additional 'cancer panel' genes above as cause for altered clinical management in endometrial cancer patients. Testing of these genes for endometrial cancer risk should only be considered as a research exercise.

\section{Evidence for proposed endometrial cancer risk genes from the analysis of germline variation in endometrial cancer patients from TCGA Project}

Details of the sequencing analysis and classification methodology are summarized in the Supplementary Text. Table 1 summarizes the information for rare germline variants detected in TCGA endometrial 
Table 1 Rare germline variants in confirmed/candidate hereditary endometrial cancer genes in TCGA endometrial cancer cases ${ }^{\mathrm{a}}$

\begin{tabular}{|c|c|c|c|c|c|c|c|c|c|c|c|c|c|c|c|c|}
\hline $\begin{array}{c}\text { Gene } \\
\text { name }\end{array}$ & Transcript ID & $\begin{array}{c}\text { Chromo- } \\
\text { some }\end{array}$ & Position-Hg-38 & $\begin{array}{l}\text { Reference } \\
\text { allele }\end{array}$ & $\begin{array}{l}\text { Alternate } \\
\text { allele }\end{array}$ & Variant effect (SnpEff) & Sample $I D(s)$ & $\begin{array}{l}\text { Minor allele } \\
\text { frequency } \\
\text { (ExaC_nonTCGA) }\end{array}$ & $r s I D$ & HGVS c. nomenclature & $\begin{array}{l}\text { HGVS } \\
\text { p. nomenclature }\end{array}$ & $\begin{array}{l}\text { MaxEntscan } \\
\text { (referenche } \\
\text { alternate } \\
\text { allele score })\end{array}$ & $\begin{array}{l}\text { Clinvar variant } \\
\text { classification } \\
\text { (submitter/s) }\end{array}$ & $\begin{array}{l}\text { Classification assigned } \\
{\text { (this study })^{\dagger}}^{\text {and }}\end{array}$ & Reported by Lu et al" & Tumor subtype \\
\hline MSH 2 & ENSTT00000233146 NM_000251.2 & 2 & 47403357 & G & $\mathrm{T}$ & Stop_gained & TCGA-D1-A108 & Null & \multicolumn{2}{|c|}{ Rs587779102 c.166G>T } & p.(Glu56Ter) & $\mathrm{NA}$ & Pathogenic (InSiGHT) I & Pathogenic: truncating & $\begin{array}{l}\text { No-assessed in } \\
\text { discovery phase only }\end{array}$ & $\mathrm{EEC}$ \\
\hline MSH 2 & ENST00000233146 NM_000251.2 & 2 & 47429943 & $\mathrm{~T}$ & c & Splice_donor_variant & TCGA-D1-A175 & Null & \multicolumn{2}{|c|}{ Rs267607953 c.1276+2T>C } & p.? & $8.92>1.17$ & $\begin{array}{l}\text { Pathogenic (GeneDx); } \\
\text { likely pathogenic (Mayo } \\
\text { Clinic Genetic Testing } \\
\text { Labs) }\end{array}$ & $\begin{array}{l}\text { Likely pathogenic: } \\
\text { likely to affect splicing, } \\
\text { MSI-H }\end{array}$ & $\begin{array}{l}\text { No-assessed in } \\
\text { discovery phase only }\end{array}$ & EEC \\
\hline MSHG & ENSTT00000234420 NM_000179.2 & 2 & 47800546 & АT & A & Frameshift_variant & TCGA-EC-A24G & Null & Null & c. $2565 \mathrm{delT}$ & p.(1le856LeuffTer12) & $\mathrm{NA}$ & Null & Pathogenic: truncating & Yes & $\mathrm{EEC}$ \\
\hline MSHG & ENSTT00000234420 NM_000179.2 & 2 & 47806605 & AAAGC & A & Frameshift_variant & TCGA-A5-AOVP & Null & Null & c.3956_3959delAAGC & p.(Ala1320GluffTer6) & $\mathrm{NA}$ & Null & Pathogenic: truncating & Yes & $\mathrm{EEC}$ \\
\hline MSH6 & ENST000000234420 NM_000179.2 & 2 & 47799111 & AAAGAG & $\therefore \mathrm{A}$ & Frameshift_variant & TCGA-AX-A1C5 & Null & \multicolumn{2}{|c|}{ Rs267608077 c.1135_1139delAGAGA } & p.(Arg379Ter) & $\mathrm{NA}$ & 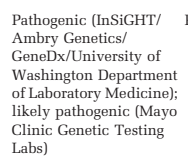 & $\begin{array}{l}\text { Pathogenic: truncating } \\
\text { t }\end{array}$ & Yes & EEC \\
\hline MSHG & ENST000000234420 NM_000179.2 & 2 & 47806842 & $\mathrm{~T}$ & TTTGA & Frameshift_variant & TCGA-BS-AOTJ & 2.43E- 03 & Rs55740729 & c.4068_4071dupGATT & p.(Lys1358AsppTer2) & $\mathrm{NA}$ & $\begin{array}{l}\text { Benign (Invitae); likely } \\
\text { benign (InSiGHT/ } \\
\text { GeneD/Ambry } \\
\text { Genetics/Illumina } \\
\text { Clinical Services } \\
\text { Laboratory) }\end{array}$ & $\begin{array}{l}\text { Likely benign } \\
\text { (truncating at } \\
3^{\prime} \text { end of gene) }\end{array}$ & Yes & EEC \\
\hline MSHG & ENST00000234420 NM__000179.2. & 2 & 47799750 & TC & $\mathrm{T}$ & Frameshift_variant & TCGA-AI-A3NE & Null & Null & c.1772delC & p.(Pro591Glinfs:Ter19) & $\mathrm{NA}$ & $\begin{array}{l}\text { Pathogenic (Ambry } \\
\text { Genetics) }\end{array}$ & Pathogenic: truncating & Yes & EEC \\
\hline MSHG & ENST00000234420 NM_000179.2 & 2 & 47798826 & A & $\mathrm{AAC}$ & Frameshift_variant & TCGA-D1-A167 & Null & \multicolumn{2}{|c|}{ Rs5752540976 c.843_844insAC } & p.(Val282ThrssTer10) & $\mathrm{NA}$ & Null & Pathogenic: truncating & Yes & $\mathrm{EEC}$ \\
\hline MSH 6 & ENST00000234420 NM_000179.2 & 2 & 47806652 & GTAAC & G & Splice_donor_variant & $\begin{array}{l}\text { TCGA-AP-A1DM; } \\
\text { TCGA-BG-A0VZ; } \\
\text { TCGA-BG-A187 }\end{array}$ & $1.27 \mathrm{E}-03$ & \multicolumn{2}{|c|}{$\begin{array}{c}\text { Rs267608132 C.4001+12 } 4001 \\
\text { +15delACTA }\end{array}$} & p.? & $6.25>6.25$ & $\begin{array}{l}\text { Uncertain (InSSiGHT/ } \\
\text { Ambry Genetics/Mayo } \\
\text { Clinic Genetic Testing } \\
\text { Laboratories); benign } \\
\text { (Geneldx/Initiea//momory } \\
\text { Genetics Laboratory); } \\
\text { Likely Benign (Counsyl) }\end{array}$ & $\begin{array}{l}\text { Uncertain: no predicted } \\
\text { effect on splicing, } 2 \\
\text { MSI-H and } 1 \text { MSI-L } \\
\text { tumor }\end{array}$ & № & EEC; EEC; EEC \\
\hline PMS2 & ENST00000265849 NM_000535.6 & 7 & 5986883 & G & A & Stop_gained & TCGA-DF-A2KY & $2.83 \mathrm{E}-05$ & Rs63750451 & c. $1882 \mathrm{C}>\mathrm{T}$ & p.(Arg628Ter) & $\mathrm{NA}$ & $\begin{array}{l}\text { Pathogenic (InSiGHT/ } \\
\text { Ambry Genetics/ } \\
\text { GeneDx/OMIM) }\end{array}$ & Pathogenic: truncating & Yes & EEC \\
\hline PMS2 & ENST000002658499 NM__000535.6 & 7 & 5987078 & G & A & Stop_gained & $\begin{array}{l}\text { TCGA-B5-A11G; } \\
\text { TCGA-B5-A3FC }\end{array}$ & Null & \multicolumn{2}{|c|}{ Rs5877786618 c.1687C>T } & p.(Arg563Ter) & $\mathrm{NA}$ & $\begin{array}{l}\text { Pathogenic (Ambry } \\
\text { Genetics/GeneDx) }\end{array}$ & Pathogenic: truncating & Yes & EEC; EEC \\
\hline PTEN & ENST00000371953 NM__000314.6 & 10 & 87957961 & CTG & c & Frameshift_variant & TCGA-QF-A5YT & Null & \multicolumn{2}{|c|}{ Rs780264945 c.750_751delTG } & p.(Cys250TTrpfsTer2) & $\mathrm{NA}$ & Null & Pathogenic: truncating & $\begin{array}{l}\text { No-assessed in } \\
\text { discovery phase } \\
\text { only }\end{array}$ & $\mathrm{EEC}$ \\
\hline$B R C A 1$ & ENSTO0000357654 NM_007294.3 & 17 & 43124027 & ACT & A & Frameshift_variant & TCGA-BS-A0TI & $2.17 \mathrm{E}-04$ & \multicolumn{2}{|c|}{ Rss386833395 c.68_69delAG } & p.(Glu23ValfsTer17) & $\mathrm{NA}$ & 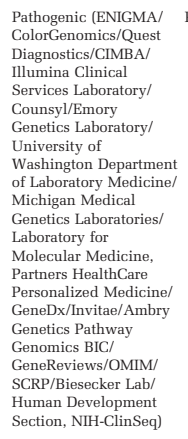 & Pathogenic: truncating & Yes & EEC \\
\hline BRCA1 & ENST00000357654 NM_007294.3 & 17 & 43082517 & $\mathrm{TC}$ & $\mathrm{T}$ & Frameshift_variant & TCGA-BG-A0M8 & Null & \multicolumn{2}{|l|}{ Rs80357981 } & p.(Glu141515ysfSTer4) & $\mathrm{NA}$ & $\begin{array}{l}\text { Pathogenic (ENIGMA } \\
\text { CIMBA/Ambry } \\
\text { Genetics/BIC/CSCRP) }\end{array}$ & Pathogenic: truncating & Yes & EEC \\
\hline
\end{tabular}




\begin{tabular}{|c|c|c|c|c|c|c|c|c|c|c|c|c|c|c|c|c|c|}
\hline $\begin{array}{l}\text { Gene } \\
\text { name }\end{array}$ & Transcript ID & Clinvar NM & $\begin{array}{c}\text { Chromo- } \\
\text { some }\end{array}$ & Position-Hg-38 & 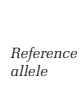 & $\begin{array}{l}\text { Alternate } \\
\text { allele }\end{array}$ & Variant effect (SnpEff) & Sample ID(s) & $\begin{array}{l}\text { Minor allele } \\
\text { frequency } \\
\text { (ExaC_nonTCGA) }\end{array}$ & $r s I D$ & HGVS c. nomenclature & $\begin{array}{l}\text { HGVS } \\
\text { p. nomenclature }\end{array}$ & $\begin{array}{l}\text { MaxEntScan } \\
\text { (reference>> } \\
\text { alternate } \\
\text { allele score) }\end{array}$ & $\begin{array}{l}\text { Clinvar variant } \\
\text { classification } \\
\text { (submitterss) }\end{array}$ & 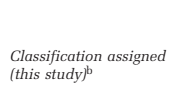 & Reported by Lu et al $l^{c}$ & Tumor subtype \\
\hline BRCA1 & ENST00000035765 & NM_007294.3 & 17 & 43091783 & c & A & Stop_gained & TCGA-A5-AOGJ & $9.42 E-06$ & Rs28897686 & c. $3748 \mathrm{G}>\mathrm{T}$ & p.(Glu1250Ter) & $\mathrm{NA}$ & $\begin{array}{l}\text { Pathogenic (ENIGMA/ } \\
\text { CIMBA/Ambry } \\
\text { Genetics/University of } \\
\text { Washington Department } \\
\text { of Laboratory Medicine, } \\
\text { University of } \\
\text { Washington/Quest } \\
\text { Diagnostics Nichols } \\
\text { Institute San Juan } \\
\text { Capistrano/IInvitae/ } \\
\text { GeneDx/SCRP/BIC/ } \\
\text { OMIM) }\end{array}$ & Pathogenic: truncating & Yes & EEC \\
\hline TP53 & ENST00000026930 & NM_000546.5 & 17 & 7675237 & c & Ст & Splice_acceptor_variant & TCGA-AP-A059 & $9.42 E-06$ & Rs751253294 & c.376-2dupA & $\mathrm{p} . ?$ & $10.63>5.09$ & $\begin{array}{l}\text { Uncertain (Ambry } \\
\text { Genetics/Invitae/ } \\
\text { GeneDx) }\end{array}$ & $\begin{array}{l}\text { Uncertain: predicted } \\
\text { effect on splicing, but } \\
\text { score change suggests } \\
\text { partial effect }\end{array}$ & $\begin{array}{l}\text { No-assessed in } \\
\text { discovery phase only }\end{array}$ & EEC \\
\hline MUTYH & ENST0000045031 & NM_001128425.1 & 1 & 45332088 & $\mathrm{~T}$ & c & Splice_acceptor_variant & TCGA-BS-AOUT & $1.09 \mathrm{E}-03$ & Rs77542170 & c. $934-2 \mathrm{~A}>\mathrm{G}$ & $\mathrm{p} . ?$ & $7.48>-0.48$ & 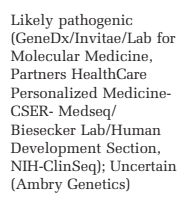 & $\begin{array}{l}\text { Likely pathogenic: } \\
\text { likely to affect splicing } \\
\text {. }\end{array}$ & Yes & EEC \\
\hline NTHL 1 & ENST0000021906 & NM_002528.6 & 16 & 2046238 & G & A & Stop_gained & $\begin{array}{l}\text { TCGA-D1-A17F; } \\
\text { TCGA-EO-A22X }\end{array}$ & $1.59 \mathrm{E}-03$ & Rs150766139 & $c .268 \mathrm{C}>\mathrm{T}$ & p.(Gln900Ter) & $\mathrm{NA}$ & Pathogenic (OMIM) & $\begin{array}{l}\text { Pathogenic: evidence of } \\
\text { functional effect in } \\
\text { colorectal cancer }\end{array}$ & Not assessed & $\mathrm{EEC} ; \mathrm{EEC}$ \\
\hline FAN1 & ENST0000036206 & NM_014967.4 & 15 & 30914092 & G & A & Splice_donor_variant & TCGA-BG-A220 & $9.42 \mathrm{E}-06$ & Rs766292876 & c. $1811+1 \mathrm{G}>\mathrm{A}$ & $\mathrm{p} ? ?$ & $10.8>2.58$ & Null & $\begin{array}{l}\text { Likely pathogenic: } \\
\text { predicted effect on } \\
\text { splicing }\end{array}$ & Not assessed & EEC \\
\hline FAN1 & ENST00000036206 & NM_014967.4 & 15 & 30937260 & G & A & Splice_donor_variant & 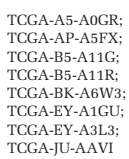 & $3.56 \mathrm{E}-03$ & Rs114680636 & c. ${ }^{*} 3+1 \mathrm{G}>\mathrm{A}$ & p.? & $9.26>1.08$ & Null & $\begin{array}{l}\text { Likely pathogenic: } \\
\text { predicted effect } \\
\text { on splicing }\end{array}$ & Not assessed & $\begin{array}{l}\text { EEC; mixed; } \\
\text { EEC; EEC; EEC; } \\
\text { EEC; SEC; SEC }\end{array}$ \\
\hline BRIP1 & ENST0000025900 & NM_032043.2 & 17 & 61683849 & GA & G & Frameshift_variant & TCGA-AP-A052 & $2.83 \mathrm{E}-05$ & Rs730881645 & c.3196delT & p.(Ser1066HisfsTer12) & $\mathrm{NA}$ & $\begin{array}{l}\text { Uncertain (GeneDx/ } \\
\text { Ambry Genetics) }\end{array}$ & $\begin{array}{l}\text { Gene of uncertain } \\
\text { significance for } \\
\text { cancer risk }\end{array}$ & Yes & SEC \\
\hline BRIP1 & ENST00000025900 & 3 NM_032043.2 & 17 & 61683837 & GA & G & Frameshift_variant & TCGA-EO-AзBо & Null & Null & c.3208delT & p.(Ser1070GlnffsTer8) & $\mathrm{NA}$ & Null & $\begin{array}{l}\text { Gene of uncertain } \\
\text { significance for } \\
\text { cancer risk }\end{array}$ & Yes & EEC \\
\hline NBN & ENST0000026543 & 3M_002485.4 & 8 & 89971173 & СтGтT & c & Frameshift_variant & TCGA-B5-A11N & $2.83 \mathrm{E}-05$ & Rs587780100 & c.698_701delAACA & p.(Lysz233SerfsTer5) & $\mathrm{NA}$ & 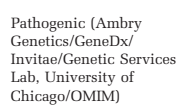 & $\begin{array}{l}\text { Pathogenic variant } \\
\text { for NBS: truncating } \\
\text { f(moderate riks for } \\
\text { breast cancer) }\end{array}$ & Yes & EEC \\
\hline
\end{tabular}

Abbreviations: ACMG, Annual Clinical Genetics Meeting; ENIGMA, Evidence-based Network for the Interpretation of Germline Mutant Alleles; HGVS, Human Genome Variation Society; MMR, mismatch repair; NA, not applicable; null, not present in database/s; TCGA, The Cancer Genome Atlas.

All patients are postmenopausal women except A0M8 (between pre- and postmenopausal) and A187 (information not available).

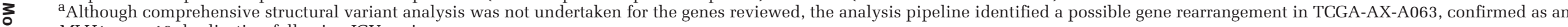

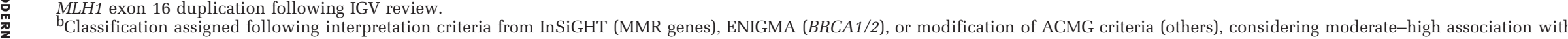
endometrial and/or other cancers.

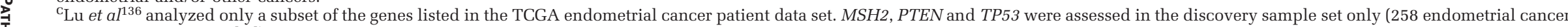
patients, IDs not provided). 
Table 2 Evidence to support clinical vs research testing of genes implicated in hereditary endometrial cancer.

\begin{tabular}{|c|c|c|c|c|c|c|c|}
\hline Syndrome & Gene(s) & $\begin{array}{l}\text { Endometrial cancer risk } \\
\text { associated with variants } \\
\text { deleterious to gene/protein } \\
\text { function }\end{array}$ & $\begin{array}{l}\text { Other cancer types associated } \\
\text { with variants deleterious to } \\
\text { gene/protein function }\end{array}$ & $\begin{array}{l}\text { Clinically actionable for } \\
\text { prediction and prevention } \\
\text { of non-endometrial cancer } \\
\text { types? }\end{array}$ & Cancer risk management strategies ${ }^{\mathrm{a}}$ & References & \\
\hline Lynch syndrome & $\begin{array}{l}\text { MLH1, MSH2, } \\
\text { MSH6, PMS2, } \\
\text { EPCAM (deletion) }\end{array}$ & High lifetime risk (18-71\%) & $\begin{array}{l}\text { Colorectal, ovarian, gastric, } \\
\text { various other }\end{array}$ & Yes & $\begin{array}{l}\text { - Colonoscopy/polypectomy } \\
\text { - Gynecological screening } \\
\text { - Risk-reducing hysterectomy and } \\
\text { salpingo-oophorectomy } \\
\text { •Endoscopy }\end{array}$ & 38,111 & \\
\hline $\begin{array}{l}\text { Polymerase proofreading- } \\
\text { associated polyposis }\end{array}$ & POLD1, POLE & $\begin{array}{l}\text { Unknown Limited data } \\
\text { suggests moderate/high }\end{array}$ & Colorectal, gastric, various other & Uncertain & $\begin{array}{l}\text { Currently, no consensus guidelines, } \\
\text { but suggested management may include: } \\
\text { •Colonoscopy/polypectomy } \\
\text { •Endoscopy } \\
\text { •Endometrial screening }\end{array}$ & 45 & 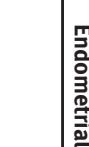 \\
\hline Cowden syndrome & PTEN & High lifetime risk (19-28\%) & $\begin{array}{l}\text { Thyroid, breast, colorectal, } \\
\text { various other }\end{array}$ & Yes & $\begin{array}{l}\text {-Endometrial screening } \\
\text { - Risk-reducing hysterectomy } \\
\text { - Mammography } \\
\text { - Possibly risk-reducing mastectomy } \\
\text { - Examination of the thyroid } \\
\text { - Colonoscopy/polypectomy }\end{array}$ & 59,60 & 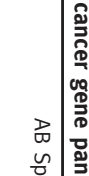 \\
\hline $\begin{array}{l}\text { Hereditary breast- } \\
\text { ovarian cancer syndrome }\end{array}$ & $B R C A 1, B R C A 2$ & $\begin{array}{l}\text { Uncertain, given possible } \\
\text { confounding with tamoxifen } \\
\text { use: if proven, likely modest } \\
\text { ( }<2 \text {-fold) }\end{array}$ & $\begin{array}{l}\text { Breast, male breast, ovarian/ } \\
\text { fallopian tube/peritoneal, } \\
\text { pancreatic, prostate }\end{array}$ & Yes & $\begin{array}{l}\text {-Mammography, breast magnetic resonance } \\
\text { imaging } \\
\text { • Risk-reducing medication } \\
\text { • Risk-reducing mastectomy } \\
\text { • Risk-reducing salpingo-oophorectomy }\end{array}$ & $\begin{array}{l}\text { Various sources, } \\
\text { summarized in } \\
\text { Petrucelli } \text { et al }{ }^{137} \\
\text { and Easton } \text { et } a l^{17}\end{array}$ & 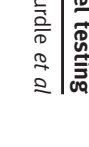 \\
\hline Li-Fraumeni syndrome & TP53 & $\begin{array}{l}\text { Unknown } \\
\text { If proven, likely modest }\end{array}$ & $\begin{array}{l}\text { Soft-tissue and bone sarcomas, } \\
\text { breast, brain, adrenocortical, } \\
\text { various other }\end{array}$ & Yes & $\begin{array}{l}\text { Currently, no consensus guidelines, but } \\
\text { may include: } \\
\text { • Breast magnetic resonance imaging } \\
\text { - Risk-reducing mastectomy } \\
\text { - Whole-body magnetic resonance imaging } \\
\text { - Biochemical surveillance } \\
\text { - Radiotherapy may be contraindicated for } \\
\text { cancer treatment }\end{array}$ & $86-89$ & \\
\hline CHEK2-associated cancer & CHEK2 & $\begin{array}{l}\text { Unknown Limited data } \\
\text { suggests risk is likely modest } \\
<2 \text {-fold }\end{array}$ & Breast & Yes & $\begin{array}{l}\text { For patients with suspected familial breast } \\
\text { cancer: } \\
\text { • Mammography, breast magnetic resonance } \\
\text { imaging }\end{array}$ & 138 & \\
\hline $\begin{array}{l}\text { MUTYH-associated } \\
\text { polyposis }\end{array}$ & MUTYH & $\begin{array}{l}\text { Monoallelic carriers-limited } \\
\text { data suggests modest ( 2-fold), } \\
\sim 4 \% \text { lifetime risk } \\
\text { Biallelic carriers- unknown }\end{array}$ & Biallelic: Colorectal, duodenal & Yes: biallelic only & $\begin{array}{l}\text { - Colonoscopy/polypectomy } \\
\text {-Endoscopy } \\
\text { - Risk-reducing colectomy }\end{array}$ & $38,111,104$ & \\
\hline Peutz-Jeghers syndrome & STK11/LKB1 & 9\% (based on limited data) & $\begin{array}{l}\text { Colorectal, pancreatic, breast, } \\
\text { ovarian, other }\end{array}$ & Yes & $\begin{array}{l}\text { • Colonoscopy/polypectomy } \\
\text { •Enteroscopy } \\
\text { •Mammography, breast magnetic resonance } \\
\text { imaging } \\
\text { • Gynecological screening } \\
\text { •Pancreatic screening }\end{array}$ & 111 & \\
\hline Cowden-like syndrome & $\begin{array}{l}\text { SDHB, SDHC, } \\
\text { SDHD, AKT1, } \\
\text { PIK3CA, KLLN, } \\
\text { and SEC } 23 B\end{array}$ & $\begin{array}{l}\text { Unknown Limited data } \\
\text { suggests risk is modest- } \\
\text { moderate ( } \sim 2.5 \text {-fold). }\end{array}$ & $\begin{array}{l}\text { SDH genes: paraganglioma, } \\
\text { renal, gastrointestinal stromal } \\
\text { sarcoma }\end{array}$ & Yes: $S D H$ genes only & $\begin{array}{l}\text {-Biochemical surveillance } \\
\text {-Magnetic resonance imaging }\end{array}$ & 118 & \\
\hline
\end{tabular}




\begin{tabular}{|c|c|c|c|c|c|c|}
\hline Syndrome & Gene(s) & $\begin{array}{l}\text { Endometrial cancer risk } \\
\text { associated with variants } \\
\text { deleterious to gene/protein } \\
\text { function }\end{array}$ & $\begin{array}{l}\text { Other cancer types associated } \\
\text { with variants deleterious to } \\
\text { gene/protein function }\end{array}$ & $\begin{array}{l}\text { Clinically actionable for } \\
\text { prediction and prevention } \\
\text { of non-endometrial cancer } \\
\text { types? }\end{array}$ & Cancer risk management strategies ${ }^{\mathrm{a}}$ & References \\
\hline RINT1-associated cancer & RINT1 & $\begin{array}{l}\text { Unknown Association not } \\
\text { replicated in a study with } \\
\text { power to detect a 2-fold risk }\end{array}$ & Breast, colorectal, other & No & None yet & N/A \\
\hline NTLH1-associated cancer & NTLH1 & $\begin{array}{l}\text { Unknown Limited data } \\
\text { suggests risk for homozygote } \\
\text { carriers only }\end{array}$ & Colorectal, various others & No & None yet & N/A \\
\hline FAN1-associated cancer & FAN1 & $\begin{array}{l}\text { Unknown Limited data } \\
\text { suggests moderate-high risk }\end{array}$ & Colorectal, various others & $\mathrm{No}^{\mathrm{b}}$ & None yet & N/A \\
\hline $\begin{array}{l}\text { Familial adenomatous } \\
\text { polyposis }\end{array}$ & $A P C$ & $\begin{array}{l}\text { High lifetime risk (close to } \\
100 \% \text { for colorectal cancer) }\end{array}$ & $\begin{array}{l}\text { Colorectal, duodenal, thyroid, } \\
\text { desmoid }\end{array}$ & Yes & $\begin{array}{l}\text { •Colonoscopy/polypectomy } \\
\text { •Endoscopy } \\
\text { • Risk-reducing colectomy }\end{array}$ & 38,111 \\
\hline \multirow[t]{2}{*}{ PALB2-associated cancer } & \multirow[t]{2}{*}{ PALB2 } & \multirow[t]{2}{*}{ Unknown } & \multirow[t]{2}{*}{ Breast, pancreatic } & $\begin{array}{l}\text { Yes: } \\
\text { Monoallelic for predicted } \\
\text { truncating variants only for } \\
\text { high risk of breast cancer }\end{array}$ & $\begin{array}{l}\text { No formal recommendations, but suggestions } \\
\text { include: } \\
\text { •Increased surveillance for breast cancer }\end{array}$ & 132 \\
\hline & & & & $\begin{array}{l}\text { Biallelic for loss-of-function } \\
\text { variants-for Fanconi anemia }\end{array}$ & $\begin{array}{l}\text { Biallelic carriers of loss-of-function variants } \\
\text { would be managed for multiple phenotypic } \\
\text { manifestations of Fanconi anemia, in } \\
\text { addition to cancer risk }\end{array}$ & 139 \\
\hline \multirow[t]{3}{*}{$\begin{array}{l}\text { Ataxia-Telangiectasia } \\
\text { syndrome }\end{array}$} & \multirow[t]{3}{*}{$A T M$} & \multirow[t]{3}{*}{ Unknown } & \multirow[t]{3}{*}{ Breast, various other } & $\begin{array}{l}\text { Yes: } \\
\text { Monoallelic for c.7271C }>\mathrm{G}- \\
\text { for high risk of breast cancer }\end{array}$ & $\begin{array}{l}\text { Monoallelic carriers of c. } 7271 \mathrm{C}>\mathrm{G} \text { : } \\
\text { •Breast cancer risk management as for } \\
\text { BRCA2 carriers }\end{array}$ & 131 \\
\hline & & & & $\begin{array}{l}\text { Monoallelic for other loss-of- } \\
\text { function variants-for } \\
\text { moderate risk of breast cancer }\end{array}$ & $\begin{array}{l}\text { Monoallelic carriers of other loss-of-function } \\
\text { variants (eg, truncating variants): } \\
\text { •Increased surveillance for breast cancer }\end{array}$ & 133 \\
\hline & & & & $\begin{array}{l}\text { Biallelic for any loss-of- } \\
\text { function variant for ataxia } \\
\text { telangiectasia }\end{array}$ & $\begin{array}{l}\text { Biallelic carriers of loss-of-function variants } \\
\text { would be managed for multiple phenotypic } \\
\text { manifestations of ataxia telangiectasia, in } \\
\text { addition to cancer risk }\end{array}$ & 140 \\
\hline Fanconi anemia & $\begin{array}{l}\text { BRIP } 1 / F A N C J \\
\text { FANCC } \\
\text { RAD51C/FANCO }\end{array}$ & Unknown & $\begin{array}{l}\text { Uncertain (but no breast cancer } \\
\text { risk for } B R I P 1 \text { ) }\end{array}$ & $\begin{array}{l}\text { Yes: biallelic only for Fanconi } \\
\text { anemia }\end{array}$ & $\begin{array}{l}\text { Biallelic carriers of loss-of-function variants } \\
\text { would be managed for multiple phenotypic } \\
\text { manifestations of Fanconi anemia, in } \\
\text { addition to cancer risk }\end{array}$ & 139 \\
\hline $\begin{array}{l}\text { Nijmegen breakage } \\
\text { syndrome }\end{array}$ & $N B N$ & Unknown & Uncertain & $\begin{array}{l}\text { Yes: biallelic only for } \\
\text { Nijmigen breakage syndrome }\end{array}$ & $\begin{array}{l}\text { Biallelic carriers of loss-of-function variants } \\
\text { would be managed for multiple phenotypic } \\
\text { manifestations of Nijmegen breakage } \\
\text { syndrome, in addition to cancer risk }\end{array}$ & 141 \\
\hline
\end{tabular}

Abbreviation: N/A, not applicable.

For the subset of genes noted in bold, the level of evidence for association with high risk of endometrial cancer is considered sufficient to support clinical testing of endometrial cancer patients. ${ }^{\mathrm{a}}$ Unless otherwise noted, management strategies listed are those considered to be usual recommendations applied for patients ascertained in the familial cancer setting.

${ }^{b}$ FAN1 - biallelic loss of function is associated with early-onset kidney dysfunction, but there are no established guidelines for management of hereditary kidney dysfunction. 
cancer patients, ${ }^{4}$ and for genes described in this review as known or potentially involved in endometrial cancer predisposition. The majority of presumed or likely pathogenic variants identified were in the MMR genes (2 MSH2, 5 MSH6, 2 PMS2 (in 3 patients)), observed in $10 / 543(1.8 \%)$ of patients. These results confirm the importance of MMR genes in endometrial cancer gene panel testing. Additional presumed or likely pathogenic variants were identified in PTEN $(n=1), B R C A 1$ ( $n=3$, all endometrioid), MUTYH ( $n=1$, heterozygote), NTLH1 $(n=1)$, FAN1 $(n=2)$, and $N B N(n=1)$, providing additional evidence that pathogenic variants in these genes should be considered for inclusion in future populationbased research studies estimating EC risk.

\section{Conclusions}

This review, combined with analysis of publicly available data for endometrial cancer patients, provides a comprehensive report of current evidence to guide the selection of genes for clinical and research gene testing of endometrial cancer patients (summarized in Table 2). Based on well-established association with endometrial cancer risk and agreed clinical management guidelines, only six genes are currently considered appropriate for clinical 'diagnostic' testing of an individual with endometrial cancer-the MMR genes (MLH1, MSH2, MSH6, PMS2), EPCAM deletion due to its effect on $\mathrm{MSH} 2$, and PTEN. Although POLD1 and POLE have recently been suggested as familial endometrial cancer genes, absolute risks for endometrial and even other cancer types are very uncertain, so the clinical utility of testing is not yet firm. At present, there is insufficient evidence to support testing BRCA1/2 in patients with isolated serous endometrial cancer in the absence of a relevant personal/family history of breast/ovarian cancer. BRCA1/2 and other genes reported as implicated in inherited endometrial cancer are at best likely to be associated with moderate or low risk of endometrial cancer. It is recommended that testing of these additional genes in endometrial cancer cases should be considered a research exercise, with need for careful patient counseling to distinguish between test results relevant to hereditary endometrial cancer and those that are actionable incidental findings due to their association with risk of other (non-endometrial) cancers (outlined in Table 2). Research testing of both familial and unselected endometrial cancer cases will be necessary to re-evaluate the descriptions of known inherited cancer syndromes, and to estimate the contribution of specific genes and variant types to the etiology of endometrial cancer at the population level. Taken together, such information will drive meaningful clinical genetic testing and counseling of endometrial cancer patients in the future.

\section{Acknowledgments}

We thank Nic Waddell and Stephen Kazakoff for assistance with TCGA sequence data analysis, Tracy O'Mara for assistance with collating TCGA phenotype data, and Emma Tudini and Michael Parsons for assistance with HGVS nomenclature checks and corrections. ABS is supported by an NHMRC Senior Research Fellowship (ID1061779). MAB and JS have been supported by QIMR Berghofer $\mathrm{PhD}$ scholarships.

\section{Disclosure/conflict of interest}

The authors declare no conflict of interest.

\section{References}

1 Howlader NNA, Krapcho M, Garshell J, et al. (eds). SEER Cancer Statistics Review, 1975-2011. National Cancer Institute: Bethesda, MD, USA. 2014.

2 Australia AIoHaWC. Gynaecological Cancers in Australia: An Overview, Cancer Series No. 70, Cat. No. CAN 66. AIHW: Canberra, 2012.

3 Amant F, Moerman P, Neven P, et al. Endometrial cancer. Lancet 2005;366:491-505.

4 Cancer Genome Atlas Research N, Kandoth C, Schultz N, et al. Integrated genomic characterization of endometrial carcinoma. Nature 2013;497:67-73.

5 Webb PM. Environmental (nongenetic) factors in gynecological cancers: update and future perspectives. Fut Oncol 2015;11:295-307.

$6 \mathrm{Hu}$ R, Hilakivi-Clarke L, Clarke R. Molecular mechanisms of tamoxifen-associated endometrial cancer [review]. Oncol Lett 2015;9:1495-1501.

7 Win AK, Reece JC, Ryan S. Family history and risk of endometrial cancer: a systematic review and metaanalysis. Obstet Gynecol 2015;125:89-98.

8 Spurdle AB, Thompson DJ, Ahmed S, et al. Genomewide association study identifies a common variant associated with risk of endometrial cancer. Nat Genet 2011;43:451-454.

9 Painter JN, O'Mara TA, Batra J, et al. Fine-mapping of the HNF1B multicancer locus identifies candidate variants that mediate endometrial cancer risk. Hum Mol Genet 2015;24:1478-1492.

10 Carvajal-Carmona LG, O'Mara TA, Painter JN, et al. Candidate locus analysis of the TERT-CLPTM1L cancer risk region on chromosome 5p15 identifies multiple independent variants associated with endometrial cancer risk. Hum Genet 2015;134:231-245.

11 Setiawan VW, Doherty JA, Shu XO, et al. Two estrogen-related variants in CYP19A1 and endometrial cancer risk: a pooled analysis in the Epidemiology of Endometrial Cancer Consortium. Cancer Epidemiol Biomarkers Prev 2009;18:242-247.

12 O'Mara TA, Glubb DM, Painter JN, et al. Comprehensive genetic assessment of the ESR1 locus identifies a risk region for endometrial cancer. Endocr Relat Cancer 2015;22:851-861.

13 Cheng TH, Thompson D, Painter J, et al. Meta-analysis of genome-wide association studies identifies common susceptibility polymorphisms for colorectal and 
endometrial cancer near SH2B3 and TSHZ1. Sci Rep 2015;5:17369.

14 Chen MM, O'Mara TA, Thompson DJ, et al. GWAS meta-analysis of 16852 women identifies new susceptibility locus for endometrial cancer. Hum Mol Genet 2016;25:2612-2620.

15 Cheng TH, Thompson DJ, O'Mara TA, et al. Five endometrial cancer risk loci identified through genome-wide association analysis. Nat Genet 2016;48: 667-674.

16 Robson M. Multigene panel testing: planning the next generation of research studies in clinical cancer genetics. J Clin Oncol 2014;32:1987-1989.

17 Easton DF, Pharoah PD, Antoniou AC, et al. Genepanel sequencing and the prediction of breastcancer risk. N Engl J Med 2015;372:2243-2257.

18 Domchek SM, Bradbury A, Garber JE, et al. Multiplex genetic testing for cancer susceptibility: out on the high wire without a net? J Clin Oncol 2013;31:1267-1270.

19 Stanislaw C, Xue Y, Wilcox WR. Genetic evaluation and testing for hereditary forms of cancer in the era of next-generation sequencing. Cancer Biol Med 2016;13:55-67.

20 Slavin TP, Niell-Swiller M, Solomon I, et al. Clinical application of multigene panels: challenges of nextgeneration counseling and cancer risk management. Front Oncol 2015;5:208.

21 Ligtenberg MJ, Kuiper RP, Chan TL, et al. Heritable somatic methylation and inactivation of $\mathrm{MSH} 2$ in families with Lynch syndrome due to deletion of the 3' exons of TACSTD1. Nat Genet 2009;41:112-117.

22 Kim TM, Laird PW, Park PJ. The landscape of microsatellite instability in colorectal and endometrial cancer genomes. Cell 2013;155:858-868.

23 Buchanan DD, Tan YY, Walsh MD, et al. Tumor mismatch repair immunohistochemistry and DNA MLH1 methylation testing of patients with endometrial cancer diagnosed at age younger than 60 years optimizes triage for population-level germline mismatch repair gene mutation testing. J Clin Oncol 2014;32:90-100.

24 Haraldsdottir S, Hampel H, Tomsic J, et al. Colon and endometrial cancers with mismatch repair deficiency can arise from somatic, rather than germline, mutations. Gastroenterology 2014;147:1308-1316 e1301.

25 Sourrouille I, Coulet F, Lefevre JH, et al. Somatic mosaicism and double somatic hits can lead to MSI colorectal tumors. Fam Cancer 2013;12:27-33.

26 Mensenkamp AR, Vogelaar IP, van Zelst-Stams WA, et al. Somatic mutations in MLH1 and MSH2 are a frequent cause of mismatch-repair deficiency in Lynch syndrome-like tumors. Gastroenterology 2014;146:643-646 e648.

27 Carcangiu ML, Radice P, Casalini P, et al. Lynch syndrome-related endometrial carcinomas show a high frequency of nonendometrioid types and of high FIGO grade endometrioid types. Int J Surg Pathol 2010;18:21-26.

28 Broaddus RR, Lynch HT, Chen LM, et al. Pathologic features of endometrial carcinoma associated with HNPCC: a comparison with sporadic endometrial carcinoma. Cancer 2006;106:87-94.

29 Hampel H, Frankel W, Panescu J, et al. Screening for Lynch syndrome (hereditary nonpolyposis colorectal cancer) among endometrial cancer patients. Cancer Res 2006;66:7810-7817.
30 Buchanan DD, Tan YY, Walsh MD, et al. Reply to J. Moline et al. J Clin Oncol 2014;32:2278-2279.

31 Hampel H, Stephens JA, Pukkala E, et al. Cancer risk in hereditary nonpolyposis colorectal cancer syndrome: later age of onset. Gastroenterology 2005;129: 415-421.

32 Dowty JG, Win AK, Buchanan DD, et al. Cancer risks for MLH1 and MSH2 mutation carriers. Hum Mutat 2013;34:490-497.

33 Baglietto L, Lindor NM, Dowty JG, et al. Risks of Lynch syndrome cancers for MSH6 mutation carriers. J Natl Cancer Inst 2010;102:193-201.

34 Hendriks YM, Wagner A, Morreau H, et al. Cancer risk in hereditary nonpolyposis colorectal cancer due to MSH6 mutations: impact on counseling and surveillance. Gastroenterology 2004;127:17-25.

35 Senter L, Clendenning M, Sotamaa K, et al. The clinical phenotype of Lynch syndrome due to germline PMS2 mutations. Gastroenterology 2008;135: 419-428.

36 ten Broeke SW, Brohet RM, Tops CM, et al. Lynch syndrome caused by germline PMS2 mutations: delineating the cancer risk. J Clin Oncol 2015;33: 319-325.

37 Kempers MJ, Kuiper RP, Ockeloen CW, et al. Risk of colorectal and endometrial cancers in EPCAM deletion-positive Lynch syndrome: a cohort study. Lancet Oncol 2011;12:49-55.

38 Stoffel EM, Mangu PB, Gruber SB, et al. Hereditary colorectal cancer syndromes: American Society of Clinical Oncology Clinical Practice Guideline endorsement of the familial risk-colorectal cancer: European Society for Medical Oncology Clinical Practice Guidelines. J Clin Oncol 2015;33:209-217.

39 Palles C, Cazier JB, Howarth KM, et al. Germline mutations affecting the proofreading domains of POLE and POLD1 predispose to colorectal adenomas and carcinomas. Nat Genet 2013;45:136-144.

40 Valle L, Hernandez-Illan E, Bellido F, et al. New insights into POLE and POLD1 germline mutations in familial colorectal cancer and polyposis. Hum Mol Genet 2014;23:3506-3512.

41 Rohlin A, Zagoras T, Nilsson S, et al. A mutation in POLE predisposing to a multi-tumour phenotype. Int J Oncol 2014;45:77-81.

42 Elsayed FA, Kets CM, Ruano D, et al. Germline variants in POLE are associated with early onset mismatch repair deficient colorectal cancer. Eur J Hum Genet 2014;23:1080-1084.

43 Billingsley CC, Cohn DE, Mutch DG, et al. Polymerase varepsilon (POLE) mutations in endometrial cancer: clinical outcomes and implications for Lynch syndrome testing. Cancer 2015;121:386-394.

44 Spier I, Holzapfel S, Altmuller J, et al. Frequency and phenotypic spectrum of germline mutations in POLE and seven other polymerase genes in 266 patients with colorectal adenomas and carcinomas. Int J Cancer 2015;137:320-331.

45 Bellido F, Pineda M, Aiza G, et al. POLE and POLD1 mutations in 529 kindred with familial colorectal cancer and/or polyposis: review of reported cases and recommendations for genetic testing and surveillance. Genet Med 2016;18:325-332.

46 Church DN, Stelloo E, Nout RA, et al. Prognostic significance of POLE proofreading mutations in endometrial cancer. J Natl Cancer Inst 2015;107:402. 
47 Stambolic V, Tsao MS, Macpherson D, et al. High incidence of breast and endometrial neoplasia resembling human Cowden syndrome in pten+/- mice. Cancer Res 2000;60:3605-3611.

48 Tan MH, Mester JL, Ngeow J, et al. Lifetime cancer risks in individuals with germline PTEN mutations. Clin Cancer Res 2012;18:400-407.

49 Nieuwenhuis MH, Kets CM, Murphy-Ryan M, et al. Cancer risk and genotype-phenotype correlations in PTEN hamartoma tumor syndrome. Fam Cancer 2014;13:57-63.

50 Riegert-Johnson DL, Gleeson FC, Roberts M, et al. Cancer and Lhermitte-Duclos disease are common in Cowden syndrome patients. Hered Cancer Clin Pract 2010;8:6.

51 Elnaggar AC, Spunt SL, Smith W, et al. Endometrial cancer in a 15-year-old girl: a complication of Cowden syndrome. Gynecol Oncol Case Rep 2012;3:18-19.

52 Baker WD, Soisson AP, Dodson MK. Endometrial cancer in a 14-year-old girl with Cowden syndrome: a case report. J Obstet Gynaecol Res 2013;39:876-878.

53 Schmeler KM, Daniels MS, Brandt AC, et al. Endometrial cancer in an adolescent: a possible manifestation of Cowden syndrome. Obstet Gynecol 2009;114: 477-479.

54 Mahdi H, Mester JL, Nizialek EA, et al. Germline PTEN, SDHB-D, and KLLN alterations in endometrial cancer patients with Cowden and Cowden-like syndromes: an international, multicenter, prospective study. Cancer 2015;121:688-696.

55 Black D, Bogomolniy F, Robson ME, et al. Evaluation of germline PTEN mutations in endometrial cancer patients. Gynecol Oncol 2005;96:21-24.

56 Ring KL, Bruegl AS, Allen BA, et al. Germline multi-gene hereditary cancer panel testing in an unselected endometrial cancer cohort. Mod Pathol 2016;29:1381-1389.

57 Susswein LR, Marshall ML, Nusbaum R, et al. Pathogenic and likely pathogenic variant prevalence among the first 10,000 patients referred for nextgeneration cancer panel testing. Genet Med 2015;18: 823-832.

58 Yurgelun MB, Allen B, Kaldate RR, et al. Identification of a variety of mutations in cancer predisposition genes in patients with suspected Lynch syndrome. Gastroenterology 2015;149:604-613 e620.

59 Ngeow J, Eng C. PTEN hamartoma tumor syndrome: clinical risk assessment and management protocol. Methods 2015;77-78:11-19.

60 Ngeow J, Sesock K, Eng C. Breast cancer risk and clinical implications for germline PTEN mutation carriers. Breast Cancer Res Treat 2015; doi:10.1007/ s10549-015-3665-z.

61 Tan MH, Mester J, Peterson C, et al. A clinical scoring system for selection of patients for PTEN mutation testing is proposed on the basis of a prospective study of 3042 probands. Am J Hum Genet 2011;88:42-56.

62 Hornreich G, Beller U, Lavie O, et al. Is uterine serous papillary carcinoma a BRCA1-related disease? Case report and review of the literature. Gynecol Oncol 1999;75:300-304.

63 Lavie O, Ben-Arie A, Pilip A, et al. BRCA2 germline mutation in a woman with uterine serous papillary carcinoma-case report. Gynecol Oncol 2005;99: $486-488$

64 Segev Y, Iqbal J, Lubinski J, et al. The incidence of endometrial cancer in women with BRCA1 and
BRCA2 mutations: an international prospective cohort study. Gynecol Oncol 2013;130:127-131.

65 Duffy DL, Antill YC, Stewart CJ, et al. Report of endometrial cancer in Australian BRCA1 and BRCA2 mutation-positive families. Twin Res Hum Genet 2011:14:111-118.

66 Shu CA, Pike MC, Jotwani AR, et al. Uterine cancer after risk-reducing salpingo-oophorectomy without hysterectomy in women with BRCA mutations. JAMA Oncol 2016;2:1434-1440.

67 Segev Y, Rosen B, Lubinski J, et al. Risk factors for endometrial cancer among women with a BRCA1 or BRCA2 mutation: a case-control study. Fam Cancer 2015;14:383-391.

68 Cuzick J, Powles T, Veronesi U, et al. Overview of the main outcomes in breast-cancer prevention trials. Lancet 2003;361:296-300.

69 Cuzick J, Sestak I, Cawthorn S, et al. Tamoxifen for prevention of breast cancer: extended long-term follow-up of the IBIS-I breast cancer prevention trial. Lancet Oncol 2015;16:67-75.

70 Thompson D, Easton DF, Breast Cancer Linkage C. Cancer Incidence in BRCA1 mutation carriers. J Natl Cancer Inst 2002;94:1358-1365.

71 Moslehi R, Chu W, Karlan B, et al. BRCA1 and BRCA2 mutation analysis of 208 Ashkenazi Jewish women with ovarian cancer. Am J Hum Genet 2000;66: 1259-1272.

72 Zakhour M, Danovitch Y, Lester J, et al. Occult and subsequent cancer incidence following risk-reducing surgery in BRCA mutation carriers. Gynecol Oncol 2016;143:231-235.

73 Bruchim I, Amichay K, Kidron D, et al. BRCA1/2 germline mutations in Jewish patients with uterine serous carcinoma. Int J Gynecol Cancer 2010;20: 1148-1153.

74 Lavie O, Ben-Arie A, Segev Y, et al. BRCA germline mutations in women with uterine serous carcinomastill a debate. Int J Gynecol Cancer 2010;20:1531-1534.

75 Pennington KP, Walsh T, Lee M, et al. BRCA1, TP53, and CHEK2 germline mutations in uterine serous carcinoma. Cancer 2013;119:332-338.

76 Barak F, Milgrom R, Laitman Y, et al. The rate of the predominant Jewish mutations in the BRCA1, BRCA2, MSH2 and MSH6 genes in unselected Jewish endometrial cancer patients. Gynecol Oncol 2010;119: $511-515$.

77 Reitsma W, Mourits MJ, de Bock GH, et al. Endometrium is not the primary site of origin of pelvic high-grade serous carcinoma in BRCA1 or BRCA2 mutation carriers. Mod Pathol 2013;26:572-578.

78 Casey MJ, Bewtra C, Lynch HT, et al. Endometrial cancers in mutation carriers from hereditary breast ovarian cancer syndrome kindreds: Report from the Creighton University Hereditary Cancer Registry With Review of the Implications. Int J Gynecol Cancer 2015;25:650-656.

79 Ciernikova S, Tomka M, Kovac M, et al. Ashkenazi founder BRCA1/BRCA2 mutations in Slovak hereditary breast and/or ovarian cancer families. Neoplasma 2006;53:97-102.

80 Surget S, Khoury MP, Bourdon JC. Uncovering the role of p53 splice variants in human malignancy: a clinical perspective. Onco Targets Ther 2013;7:57-68.

81 Ruijs MW, Verhoef S, Rookus MA, et al. TP53 germline mutation testing in 180 families suspected of Li-Fraumeni syndrome: mutation detection rate 
and relative frequency of cancers in different familial phenotypes. J Med Genet 2010;47:421-428.

82 Nichols KE, Malkin D, Garber JE, et al. Germ-line p53 mutations predispose to a wide spectrum of earlyonset cancers. Cancer Epidemiol Biomarkers Prev 2001;10:83-87.

83 Kamihara J, Rana HQ, Garber JE. Germline TP53 mutations and the changing landscape of Li-Fraumeni syndrome. Hum Mutat 2014;35:654-662.

84 Heitzer E, Lax S, Lafer I, et al. Multiplex genetic cancer testing identifies pathogenic mutations in TP53 and CDH1 in a patient with bilateral breast and endometrial adenocarcinoma. BMC Med Genet 2013;14:129.

85 Chao A, Lai CH, Lee YS, et al. Molecular characteristics of endometrial cancer coexisting with peritoneal malignant mesothelioma in Li-Fraumeni-like syndrome. BMC Cancer 2015;15:8.

86 McBride KA, Ballinger ML, Killick E, et al. Li-Fraumeni syndrome: cancer risk assessment and clinical management. Nat Rev Clin Oncol 2014;11: 260-271.

87 Custodio G, Parise GA, Kiesel Filho N, et al. Impact of neonatal screening and surveillance for the TP53 $\mathrm{R} 337 \mathrm{H}$ mutation on early detection of childhood adrenocortical tumors. J Clin Oncol 2013;31: 2619-2626.

88 Villani A, Tabori U, Schiffman J, et al. Biochemical and imaging surveillance in germline TP53 mutation carriers with Li-Fraumeni syndrome: a prospective observational study. Lancet Oncol 2011;12:559-567.

89 Anupindi SA, Bedoya MA, Lindell RB, et al. Diagnostic performance of whole-body MRI as a tool for cancer screening in children with genetic cancerpredisposing conditions. Am J Roentgenol 2015;205: 400-408.

90 Ognjanovic S, Olivier M, Bergemann TL, et al. Sarcomas in TP53 germline mutation carriers: a review of the IARC TP53 database. Cancer 2012;118: 1387-1396.

91 Cybulski C, Gorski B, Huzarski T, et al. CHEK2 is a multiorgan cancer susceptibility gene. Am J Hum Genet 2004;75:1131-1135.

92 Kilpivaara O, Vahteristo P, Falck J, et al. CHEK2 variant I157T may be associated with increased breast cancer risk. Int J Cancer 2004;111:543-547.

93 Han FF, Guo CL, Liu LH. The effect of CHEK2 variant I157T on cancer susceptibility: evidence from a metaanalysis. DNA Cell Biol 2013;32:329-335.

94 Southey MC, Goldgar DE, Winqvist R, et al. PALB2, CHEK2 and ATM rare variants and cancer risk: data from COGS. J Med Genet 2016;53:800-811.

95 Meijers-Heijboer $\mathrm{H}$, van den Ouweland A, Klijn J, et al. Low-penetrance susceptibility to breast cancer due to CHEK2 $\left(^{*}\right.$ 1100delC in noncarriers of BRCA1 or BRCA2 mutations. Nat Genet 2002;31:55-59.

96 Consortium CBCC-C. CHEK2*1100delC and susceptibility to breast cancer: a collaborative analysis involving 10,860 breast cancer cases and 9,065 controls from 10 studies. Am J Hum Genet 2004;74: 1175-1182.

97 Schmidt MK, Hogervorst F, van Hien R, et al. Age- and tumor subtype-specific breast cancer risk estimates for CHEK2*1100delC carriers. J Clin Oncol 2016;34:2750-2760.

98 Naslund-Koch C, Nordestgaard BG, Bojesen SE. Increased risk for other cancers in addition to breast cancer for CHEK2*1100delC heterozygotes estimated from the Copenhagen General Population Study. J Clin Oncol 2016;34:1208-1216.

99 de Jong MM, Nolte IM, Te Meerman GJ, et al. Colorectal cancer and the CHEK2 1100delC mutation. Genes Chromosomes Cancer 2005;43:377-382.

100 Einarsdottir K, Humphreys K, Bonnard C, et al. Effect of ATM, CHEK2 and ERBB2 TAGSNPs and haplotypes on endometrial cancer risk. Hum Mol Genet 2007;16:154-164.

101 Konstantinova DV, Kadiyska TK, Kaneva RP, et al. CHEK2 I157T and endometrial cancer. DNA Cell Biol 2009;28:9-12.

102 Suchy J, Cybulski C, Wokolorczyk D, et al. CHEK2 mutations and HNPCC-related colorectal cancer. Int J Cancer 2010;126:3005-3009.

103 Win AK, Dowty JG, Cleary SP, et al. Risk of colorectal cancer for carriers of mutations in MUTYH, with and without a family history of cancer. Gastroenterology 2014;146:1208-1211, e1201-11205.

104 Vogt S, Jones N, Christian D, et al. Expanded extracolonic tumor spectrum in MUTYH-associated polyposis. Gastroenterology 2009;137:1976-1985, e1971-e1910.

105 Win AK, Cleary SP, Dowty JG, et al. Cancer risks for monoallelic MUTYH mutation carriers with a family history of colorectal cancer. Int J Cancer 2011;129: 2256-2262.

106 Barnetson RA, Devlin L, Miller J, et al. Germline mutation prevalence in the base excision repair gene, $\mathrm{MYH}$, in patients with endometrial cancer. Clin Genet 2007;72:551-555.

107 Tricarico R, Bet P, Ciambotti B, et al. Endometrial cancer and somatic G>T KRAS transversion in patients with constitutional MUTYH biallelic mutations. Cancer Lett 2009;274:266-270.

108 Ashton KA, Proietto A, Otton G, et al. Genetic variants in MUTYH are not associated with endometrial cancer risk. Hered Cancer Clin Pract 2009;7:3.

109 Banno K, Kisu I, Yanokura M, et al. Hereditary gynecological tumors associated with Peutz-Jeghers syndrome [review]. Oncol Lett 2013;6:1184-1188.

110 Giardiello FM, Brensinger JD, Tersmette AC, et al. Very high risk of cancer in familial Peutz-Jeghers syndrome. Gastroenterology 2000;119:1447-1453.

111 Syngal S, Brand RE, Church JM, et al. ACG clinical guideline: genetic testing and management of hereditary gastrointestinal cancer syndromes. Am J Gastroenterol 2015;110:223-262, quiz 263.

112 Ni Y, Zbuk KM, Sadler T, et al. Germline mutations and variants in the succinate dehydrogenase genes in Cowden and Cowden-like syndromes. Am J Hum Genet 2008;83:261-268.

113 Ngeow J, Mester J, Rybicki LA, et al. Incidence and clinical characteristics of thyroid cancer in prospective series of individuals with Cowden and Cowdenlike syndrome characterized by germline PTEN, SDH, or KLLN alterations. J Clin Endocrinol Metab 2011;96: E2063-E2071.

$114 \mathrm{Ni}$ Y, He X, Chen J, et al. Germline SDHx variants modify breast and thyroid cancer risks in Cowden and Cowden-like syndrome via FAD/NAD-dependant destabilization of p53. Hum Mol Genet 2012;21: 300-310.

115 Orloff MS, He X, Peterson C, et al. Germline PIK3CA and AKT1 mutations in Cowden and Cowden-like syndromes. Am J Hum Genet 2013;92:76-80. 
116 Bennett KL, Mester J, Eng C. Germline epigenetic regulation of KILLIN in Cowden and Cowden-like syndrome. JAMA 2010;304:2724-2731.

117 Yehia L, Niazi F, Ni Y, et al. Germline heterozygous variants in SEC23B are associated with Cowden syndrome and enriched in apparently sporadic thyroid cancer. Am J Hum Genet 2015;97:661-676.

118 Chen H, Sippel RS, O'Dorisio MS, et al. The North American Neuroendocrine Tumor Society consensus guideline for the diagnosis and management of neuroendocrine tumors: pheochromocytoma, paraganglioma, and medullary thyroid cancer. Pancreas 2010;39:775-783.

119 Park DJ, Tao K, Le Calvez-Kelm F, et al. Rare mutations in RINT1 predispose carriers to breast and Lynch syndrome-spectrum cancers. Cancer Discov 2014;4:804-815.

120 Li N, Thompson ER, Rowley SM, et al. Reevaluation of RINT1 as a breast cancer predisposition gene. Breast Cancer Res Treat 2016;159:385-392.

121 Weren RD, Ligtenberg MJ, Kets CM, et al. A germline homozygous mutation in the base-excision repair gene NTHL1 causes adenomatous polyposis and colorectal cancer. Nat Genet 2015;47:668-671.

122 Segui N, Mina LB, Lazaro C, et al. Germline mutations in FAN1 cause hereditary colorectal cancer by impairing DNA repair. Gastroenterology 2015;149: 563-566.

123 Zhou W, Otto EA, Cluckey A, et al. FAN1 mutations cause karyomegalic interstitial nephritis, linking chronic kidney failure to defective DNA damage repair. Nat Genet 2012;44:910-915.

124 Moch H, Spondin M, Schmassmann A, et al. Systemic karyomegaly with chronic interstitial nephritis. Discussion of the disease picture based on an autopsy case. Pathologe 1994;15:44-48.

125 Burry AF. Extreme dysplasia in renal epithelium of a young woman dying from hepatocarcinoma. J Pathol 1974;113:147-150.

126 LaDuca H, Stuenkel AJ, Dolinsky JS, et al. Utilization of multigene panels in hereditary cancer predisposition testing: analysis of more than 2,000 patients. Genet Med 2014;16:830-837.

127 Seal S, Thompson D, Renwick A, et al. Truncating mutations in the Fanconi anemia J gene BRIP1 are low-penetrance breast cancer susceptibility alleles. Nat Genet 2006;38:1239-1241.

128 Easton DF, Lesueur F, Decker B, et al. No evidence that protein truncating variants in BRIP1 are asso- ciated with breast cancer risk: implications for gene panel testing. J Med Genet 2016;53:298-309.

129 Ramus SJ, Song H, Dicks E, et al. Germline mutations in the BRIP1, BARD1, PALB2, and NBN genes in women with ovarian cancer. J Natl Cancer Inst 2015;107: djv214; doi: https://doi.org/10.1093/jnci/djv214.

130 Antoniou AC, Foulkes WD, Tischkowitz M, Group PI. Breast cancer risk in women with PALB2 mutations in different populations. Lancet Oncol 2015;16: e375-e376.

131 Goldgar DE, Healey S, Dowty JG, et al. Rare variants in the ATM gene and risk of breast cancer. Breast Cancer Res 2011;13:R73.

132 PALB2_Interest_Group. PALB2 mutation and cancer risks. Available at: http://www.palb2.org/palb2-muta tion-and-cancer-risks/ 2016.

133 van Os NJ, Roeleveld N, Weemaes CM, et al. Health risks for ataxia-telangiectasia mutated heterozygotes: a systematic review, meta-analysis and evidence-based guideline. Clin Genet 2016;90:105-117.

134 Young EL, Feng BJ, Stark AW, et al. Multigene testing of moderate-risk genes: be mindful of the missense. J Med Genet 2016;53:366-376.

135 Tung N, Domchek SM, Stadler Z, et al. Counselling framework for moderate-penetrance cancer-susceptibility mutations. Nat Rev Clin Oncol 2016;13:581-588.

$136 \mathrm{Lu} \mathrm{C}$, Xie M, Wendl MC, et al. Patterns and functional implications of rare germline variants across 12 cancer types. Nat Commun 2015;6:10086.

137 Petrucelli N, Daly MB, Feldman GL. BRCA1 and BRCA2 hereditary breast and ovarian cancer. In: Pagon RA, Adam MP, Ardinger HH, et al. (eds). GeneReviews(R): University of Washington, Seattle, WA, USA, 2013.

138 Adank MA, Hes FJ, van Zelst-Stams WA, et al. CHEK2-mutation in Dutch breast cancer families: expanding genetic testing for breast cancer. Ned Tijdschr Geneeskd 2015;159:A8910.

139 Fanconi Anemia. Guidelines for Diagnosis and Management, 4th edn. Fancomi Anemia Research Func: Eugene, OR, 2014.

140 van de Warrenburg BP, van Gaalen J, Boesch S, et al. EFNS/ENS consensus on the diagnosis and management of chronic ataxias in adulthood. Eur J Neurol 2014;21:552-562.

141 Varon R, Demuth I, Digweed M. Nijmegen breakage syndrome. In: Pagon RA, Adam MP, Ardinger HH, et al. (eds). GeneReviews(R): University of Washington, Seattle, WA, USA, 2014.

Supplementary Information accompanies the paper on Modern Pathology website (http://www.nature.com/ modpathol) 